\title{
Formal guidelines: management of acute respiratory distress syndrome
}

\author{
Laurent Papazian ${ }^{1 *}$, Cécile Aubron $^{2}$, Laurent Brochard ${ }^{3}$, Jean-Daniel Chiche ${ }^{4}$, Alain Combes ${ }^{5}$, Didier Dreyfuss ${ }^{6}$, \\ Jean-Marie Forel ${ }^{1}$, Claude Guérin ${ }^{7}$, Samir Jaber ${ }^{8}$, Armand Mekontso-Dessap $^{9}$, Alain Mercat ${ }^{10}$, \\ Jean-Christophe Richard ${ }^{11}$, Damien Roux ${ }^{6}$, Antoine Vieillard-Baron ${ }^{12}$ and Henri Faure ${ }^{13}$
}

\begin{abstract}
Fifteen recommendations and a therapeutic algorithm regarding the management of acute respiratory distress syndrome (ARDS) at the early phase in adults are proposed. The Grade of Recommendation Assessment, Development and Evaluation (GRADE) methodology has been followed. Four recommendations (low tidal volume, plateau pressure limitation, no oscillatory ventilation, and prone position) had a high level of proof (GRADE $1+$ or $1-$ ); four (high positive end-expiratory pressure [PEEP] in moderate and severe ARDS, muscle relaxants, recruitment maneuvers, and venovenous extracorporeal membrane oxygenation [ECMO]) a low level of proof (GRADE 2+ or 2 -); seven (surveillance, tidal volume for non ARDS mechanically ventilated patients, tidal volume limitation in the presence of low plateau pressure, PEEP $>5 \mathrm{cmH} 2 \mathrm{O}$, high PEEP in the absence of deleterious effect, pressure mode allowing spontaneous ventilation after the acute phase, and nitric oxide) corresponded to a level of proof that did not allow use of the GRADE classification and were expert opinions. Lastly, for three aspects of ARDS management (driving pressure, early spontaneous ventilation, and extracorporeal carbon dioxide removal), the experts concluded that no sound recommendation was possible given current knowledge. The recommendations and the therapeutic algorithm were approved by the experts with strong agreement.
\end{abstract}

\section{Introduction}

Acute respiratory distress syndrome (ARDS) is an inflammatory process in the lungs that induces non-hydrostatic protein-rich pulmonary oedema. The immediate consequences are profound hypoxemia, decreased lung compliance, and increased intrapulmonary shunt and dead space. The clinicopathological aspects include severe inflammatory injury to the alveolar-capillary barrier, surfactant depletion, and loss of aerated lung tissue.

The most recent definition of ARDS, the Berlin definition, was proposed by a working group under the aegis of the European Society of Intensive Care Medicine [1]. It defines ARDS by the presence within 7 days of a known clinical insult or new or worsening respiratory symptoms of a combination of acute hypoxemia

\footnotetext{
*Correspondence: Laurent.PAPAZIAN@ap-hm.fr

1 Service de Médecine Intensive - Réanimation, Hôpital Nord, Chemin des Bourrely, 13015 Marseille, France

Full list of author information is available at the end of the article
}

$\left(\mathrm{PaO}_{2} / \mathrm{FiO}_{2} \leq 300 \mathrm{mmHg}\right)$, in a ventilated patient with a positive end-expiratory pressure (PEEP) of at least $5 \mathrm{cmH}_{2} \mathrm{O}$, and bilateral opacities not fully explained by heart failure or volume overload. The Berlin definition uses the $\mathrm{PaO}_{2} / \mathrm{FiO}_{2}$ ratio to distinguish mild ARDS $\left(200<\mathrm{PaO}_{2} / \mathrm{FiO}_{2} \leq 300 \mathrm{mmHg}\right)$, moderate ARDS $\left(100<\mathrm{PaO}_{2} / \mathrm{FiO}_{2} \leq 200 \mathrm{mmHg}\right)$, and severe ARDS $\left(\mathrm{PaO}_{2} /\right.$ $\mathrm{FiO}_{2} \leq 100 \mathrm{mmHg}$ ).

Much information on the epidemiology of ARDS has accrued from LUNG SAFE, an international, multicenter, prospective study conducted in over 29,000 patients in 50 countries [2]. During this study, ARDS accounted for $10 \%$ of admissions to intensive care unit (ICU) and 23\% of ventilated patients. Hospital mortality, which increased with the severity of ARDS [2], was about $40 \%$, and reached $45 \%$ in patients presenting with severe ARDS [2-4]. Significant physical, psychological, and cognitive sequelae, with a marked impact on quality of life, have been reported up to 5 years after ARDS [5]. 
One of the most important results of the LUNG SAFE study was that ARDS was not identified as such by the primary care clinician in almost $40 \%$ of cases [2]. This was particularly so for mild ARDS, in which only $51 \%$ of cases were identified [2]. When all ARDS criteria were met, only $34 \%$ of ARDS patients were identified, suggesting that there was a delay in adapting the treatment, in particular mechanical ventilation [2]. This is the main reason why these formal guidelines are not limited to patients presenting with severe ARDS, but are intended for application to all mechanically ventilated intensive care patients.

Results from the LUNG SAFE study suggest that the ventilator settings used did not fully respect the principles of protective mechanical ventilation [2]. Plateau pressure was measured in only $40 \%$ of ARDS patients [2]. And only two-thirds of patients for whom plateau pressure was reported were receiving protective mechanical ventilation (tidal volume $\leq 8 \mathrm{~mL} / \mathrm{kg}$ predicted body weight [PBW] and plateau pressure $\leq 30 \mathrm{cmH}_{2} \mathrm{O}$ ) [2]. Analysis of the LUNG SAFE results also shows a lack of relation between PEEP and the $\mathrm{PaO}_{2} / \mathrm{FIO}_{2}$ ratio [2]. In contrast, there was an inverse relation between $\mathrm{FIO}_{2}$ and $\mathrm{SpO}_{2}$, suggesting that the clinicians used $\mathrm{FIO}_{2}$ to treat hypoxemia. Lastly, prone positioning was used in just $8 \%$ of patients presenting with ARDS, essentially as salvage treatment [2].

The reduction in mortality associated with ARDS over the last 20 years seems to be explained largely by a decrease in ventilator-induced lung injury (VILI). VILI is essentially related to volutrauma closely associated with "strain" and "stress". Lung stress corresponds to transpulmonary pressure (alveolar pressure-pleural pressure), and lung strain refers to the change in lung volume indexed to functional residual capacity of the ARDS lung at zero PEEP. So, volutrauma corresponds to generalized excess stress and strain on the injured lung [6-8]. High-quality CT scan studies and physiological studies have revealed that lung lesions are unequally distributed, the injury or atelectasis coexisting with aerated alveoli of close-to-normal structure [9]. ARDS is not a disease; it is a syndrome defined by a numerous clinical and physiological criteria. It is therefore not surprising that lung-protective ventilatory strategies that are based on underlying physiological principles have been shown to be effective in improving outcome. Minimizing VILI thus generally aims reducing volutrauma (reduction in global stress and strain). Lowering airway pressures has the theoretical dual benefit of minimizing overdistension of the aerated areas and mitigating negative hemodynamic consequences.

The current SRLF guidelines are more than 20 years old and so there was a pressing need to update them. The main aim with these formal guidelines was voluntarily to limit the topics to the best studied fields, so as to provide practitioners with solid guidelines with a high level of agreement between experts. Certain very important aspects of ARDS management were deliberately not addressed because there is insufficient assessment of their effects on prognosis (respiratory rate, mechanical power, target oxygenation, $\mathrm{pH}, \mathrm{PaCO}_{2} \ldots$ ). We also limited these guidelines to adult patients, to early phase of ARDS (first few days), and to invasive mechanical ventilation.

\section{Methods}

These guidelines have been formulated by an expert working group selected by the SRLF. The organizing committee first defined the questions to be addressed and then designated the experts in charge of each question. The questions were formulated according to a Patient Intervention Comparison Outcome (PICO) format after a first meeting of the expert group. The literature was analyzed using Grade of Recommendation Assessment, Development and Evaluation (GRADE) methodology. A level of proof was defined for each bibliographic reference cited as a function of the type of study and its methodological quality. An overall level of proof was determined for each endpoint. The experts then formulated guidelines according to the GRADE methodology (Table 1).

A high overall level of proof enabled formulation of a "strong" recommendation (should be done... GRADE $1+$, should not be done... GRADE 1-). A moderate, low, or very low overall level of proof led to the drawing up of an "optional" recommendation (should probably be done... GRADE $2+$, should probably not be done... GRADE 2-). When the literature was inexistent or insufficient, the question could be the subject of a recommendation in the form of an expert opinion (the experts suggest...). The proposed recommendations were presented and discussed at a second meeting of the expert group. Each expert then reviewed and rated each recommendation using a scale of 1 (complete disagreement) to 9 (complete agreement). The collective rating was done using a GRADE grid methodology. To approve a recommendation regarding a criterion, at least $50 \%$ of the experts had to agree and less than $20 \%$ had to disagree. For a strong agreement, at least $70 \%$ of the experts had to agree. In the absence of strong agreement, the recommendations were reformulated and rated again, with a view to reaching a consensus (Table 2).

\section{Area 1: Evaluation of ARDS management}

R1.1 - The experts suggest that the efficacy and safety of all ventilation parameters and therapeutics associated with ARDS management should be evaluated at least every $24 \mathrm{~h}$. EXPERT OPINION 
Table 1 Recommendations according to the GRADE methodology

\begin{tabular}{|c|c|c|}
\hline \multirow[b]{2}{*}{ High level of proof } & \multicolumn{2}{|c|}{ Recommendations according to the GRADE methodology } \\
\hline & $\begin{array}{l}\text { Strong recommendation } \\
\text { "...should be done..." }\end{array}$ & Grade 1+ \\
\hline Moderate level of proof & $\begin{array}{l}\text { Optional recommendation } \\
\text { "... should probably be done..." }\end{array}$ & Grade 2+ \\
\hline Insufficient level of proof & $\begin{array}{l}\text { Recommendation in the form of an expert opinion } \\
\text { "The experts suggest..." }\end{array}$ & Expert opinion \\
\hline Moderate level of proof & $\begin{array}{l}\text { Optional recommendation } \\
\text { "... should probably not be done..." }\end{array}$ & Grade 2- \\
\hline High level of proof & $\begin{array}{l}\text { Strong recommendation } \\
\text { "... should not be done..." }\end{array}$ & Grade 1 - \\
\hline Insufficient level of proof & & No recommen \\
\hline
\end{tabular}

\section{Rationale:}

Evaluation of the efficacy and safety of mechanical ventilation settings and treatments is a cornerstone of the early phase of the management of ARDS patients. As shown in these formal guidelines, the settings of ventilation parameters, such as PEEP, are based on their eff-cacy and tolerance. Moreover, the indication for some treatments depends on the severity of ARDS and these treatments will only be implemented when there is insufficient response to first-line treatments.
Figure 1 shows the treatments implemented to patients with ARDS based on the severity of respiratory distress. The decision to initiate some treatments is taken after a "stabilization" phase [10] that includes optimization of mechanical ventilation as the first step of management. Early evaluation of efficacy based on the $\mathrm{PaO}_{2} / \mathrm{FiO}_{2}$ ratio is necessary in order to discuss the relevance of neuromuscular blocking agents and of prone positioning (Fig. 1).

The safety of drug therapies and procedures must also be regularly evaluated. These guidelines also address the

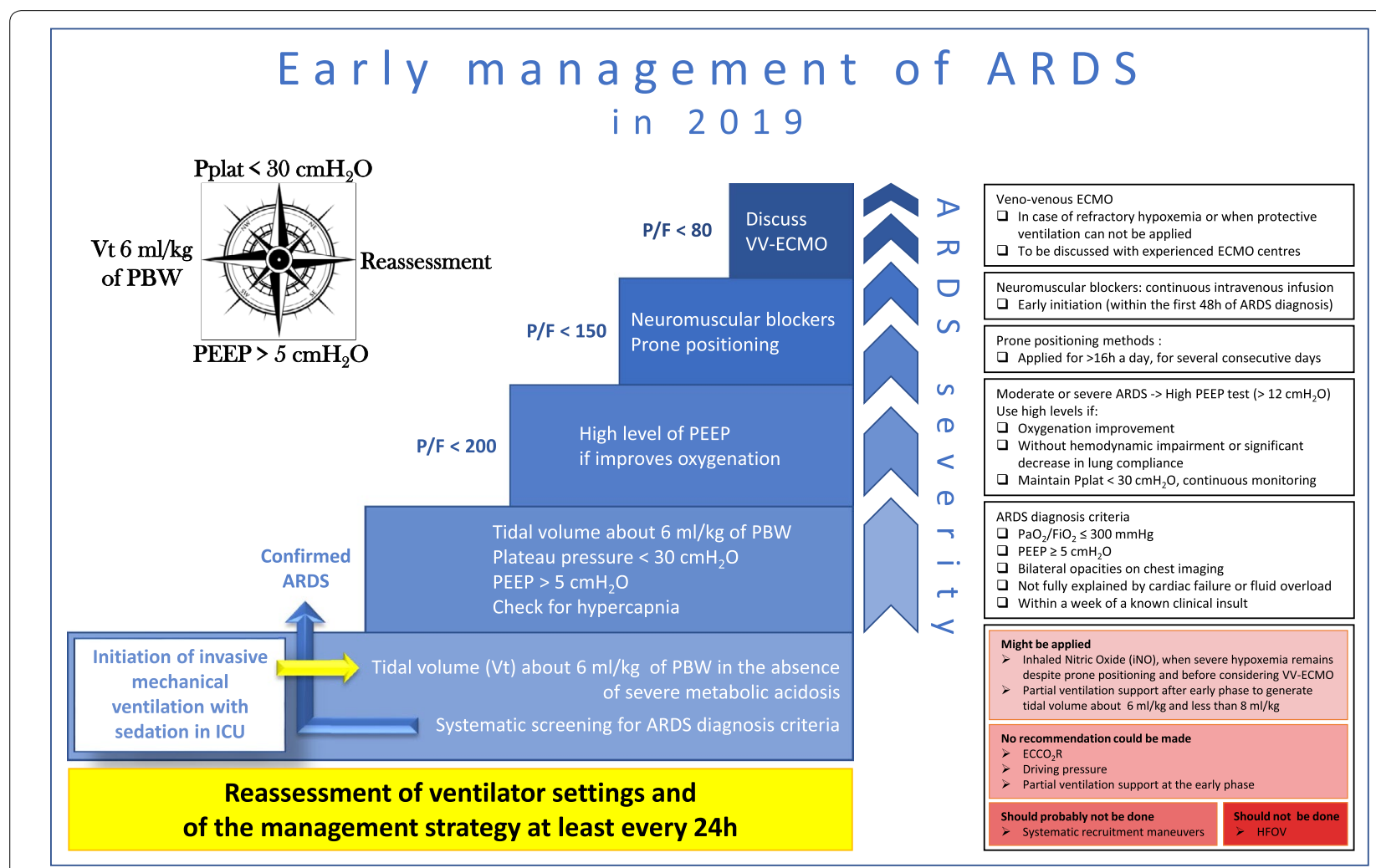

Fig. 1 Therapeutic algorithm regarding early ARDS management (EXPERT OPINION) 
main safety problems of the treatments. Literature support for such practices is lacking, and they are guided by good clinical sense.

Indeed, data are scarce on the benefits of regular assessment of ventilation settings and/or disease severity in ARDS patients. A single-center observational study has shown the value of systematic evaluation of respiratory mechanics during ARDS in the initial phase (mostly in the first $48 \mathrm{~h}$ ) [11]. In this study, evaluation of the passive mechanics of the lung and thoracic cage, of the response to PEEP, and of alveolar recruitment prompted changes in ventilation parameters in most patients (41 of 61 analyzed). These changes were associated with improvements in plateau pressure $\left(-2 \mathrm{cmH}_{2} \mathrm{O}\right.$ on average), driving pressure $\left(-3 \mathrm{~cm} \mathrm{H}_{2} \mathrm{O}\right.$ on average), and oxygenation index [11].

It is difficult to define how often to assess ventilation parameters and treatments in ARDS. It seems that a frequency at least similar to that proposed for the evaluation of criteria for weaning from the ventilator (i.e. daily) is reasonable [12]. Nonetheless, more frequent assessment might be necessary and benefit in some cases.

\section{Area 2: Tidal volume management}

Tidal volume adjustment

R2.1.1 - A tidal volume around $6 \mathrm{~mL} / \mathrm{kg}$ of predicted body weight (PBW) should be used as a first approach in patients with recognized ARDS, in the absence of severe metabolic acidosis, including those with mild ARDS, to reduce mortality.

GRADE 1 +, STRONG AGREEMENT

R2.1.2 - The experts suggest a similar approach for all patients on invasive mechanical ventilation and under sedation in ICU, given the high rate of failure to recognize ARDS and the importance of rapidly implementing pulmonary protection.

\section{EXPERT OPINION}

\section{Rationale:}

To control potentially deleterious increases in $\mathrm{PaCO}_{2}$ (which raise pulmonary arterial pressure), a relatively high respiratory rate of between 25 and 30 cycles/min should be adopted first. Too high a rate, however, engenders a risk of dynamic hyperinflation and also increases each minute cumulative exposure to potentially risky insufflation. A $\mathrm{PaCO}_{2}$ below $50 \mathrm{mmHg}$ is generally acceptable. A reduction in instrumental dead space is also appropriate, and a heated humidifier should be used in first intention.
The PBW should be calculated for each patient upon admission as a function of height and sex.

The tidal volume delivered will induce a pressure increase from the PEEP, thus necessitating monitoring of plateau pressure, which should be kept below $30 \mathrm{cmH}_{2} \mathrm{O}$.

Clinicians need to be aware of the potential risks of low tidal volume, such as dyssynchrony and double triggering. Guidelines on pressure and volume reduction issued in the late 1980s were based on experimental and clinical data [13-16]. Several randomized clinical trials with rather few subjects in the 1990s found no survival advantage of low tidal volume $[17,18]$. A lack of power may, of course, explain these negative results. Note also that these trials were not intended to achieve control of $\mathrm{PaCO}_{2}$, which may have contributed to the deleterious effects of hypercapnic acidosis in the study arms using reduced tidal volume. Although the clinical evidence is not easy to demonstrate, hypercapnia has unquestionable side effects [19], like increased pulmonary vascular resistance, which can worsen prognosis. In 2000, the ARMA study run by the NHLBI ARDS Network in the USA yielded key data comparing a pulmonary protection strategy using "low" tidal volume, on average $6 \mathrm{~mL} / \mathrm{kg}$ PBW, a plateau pressure limited to $30 \mathrm{cmH}_{2} \mathrm{O}$, and a respiratory rate up to 35 breaths $/ \mathrm{min}$, with a non-protection strategy using a tidal volume of $12 \mathrm{~mL} / \mathrm{kg}$ PBW [20]. The use of PBW calculated as a function of sex and height was an important innovation in adapting tidal volume to the expected lung volume. In this study, increased respiratory rate leading to low-volume ventilation was associated with only a minimal increase in $\mathrm{PaCO}_{2}$, a result that may have contributed to the benefits of this treatment arm. A $25 \%$ reduction in the relative risk of mortality was observed, i.e., a $30-40 \%$ decrease in overall mortality. This study had an enormous impact on clinical practice. It was not the first to use low volumes successfully, that accolade falls to the two-center study by Amato et al., but low tidal volume was combined with higher PEEP, the idea being to reduce driving pressure [21]. Other studies using the same approach as Amato et al. found a similar reduction in mortality [22]. Meta-analyses of tidal volume reduction have often included rather heterogenous studies [23]. The most recent included seven randomized trials in 1481 patients [24] and concluded that lower mortality was associated with low-volume ventilation in primary analysis (hazard ratio $0.80[0.66,0.98]$ ) and found a significant relation between tidal volume reduction and the mortality reduction effect. However, when the studies that combined high PEEP and low volumes were excluded, the effect of reduced tidal volume was just a non-significant trend $(0.87[0.70,1.08])$. According to the authors, this suggests, but does not prove, that reduced tidal volumes significantly decrease mortality 
during ARDS. In an observational study, 11,558 ventilation parameters were available for 482 ARDS patients identified prospectively [25]. The authors compared the patients with volumes of $6.5 \mathrm{~mL} / \mathrm{kg}$ PBW or less, upon admission, with patients with volumes $>6.5 \mathrm{~mL} / \mathrm{kg}$ PBW (68\% of patients), and found that, after adjustment for known confounding factors, an increase of $1 \mathrm{~mL} / \mathrm{kg}$ PBW in the settings of the initial volume was associated with a $23 \%$ increase in risk of death in intensive care (hazard ratio, 1.23; 95\% confidence interval, 1.06-1.44; $p=0.008$ ) [25]. A secondary increase in tidal volume was also associated with an increase in mortality risk, but the mortality risk of too high a first tidal volume was higher than the effect of the following volumes [25]. In the LUNG SAFE study [2], tidal volume did not seem to be a significant factor in mortality. However, the volume range was limited [26], which suggests that a "certain degree" of pulmonary protection is used very frequently, but in very few patients with tidal volumes above 10 or below $6 \mathrm{~mL} / \mathrm{kg}$. There was no difference in survival in the patients whose tidal volume was equal to or greater than the median value of $7.1 \mathrm{~mL} / \mathrm{kg}$ PBW [26]. In addition, the use of lower tidal volumes in patients with severe ARDS may involve potentially confounding effects, which are difficult to analyze completely in purely observational data [26]. In all analyses, however, the pressures (peak pressure, plateau pressure, driving pressure, and PEEP) carried more significant weight than tidal volume in the prognosis [26].

Plateau pressure

\section{R2.2.1 - Once tidal volume is set to around $6 \mathrm{~mL} / \mathrm{kg}$ PBW, plateau pressure should be moni- tored continuously and should not exceed $\mathbf{3 0}$ $\mathrm{CmH}_{2} \mathrm{O}$ to reduce mortality. GRADE 1 +, STRONG AGREEMENT}

\section{R2.2.2 - The experts suggest that tidal volume should not be increased when the plateau pres- sure is well below $30 \mathrm{cmH}_{2} \mathrm{O}$, except in cases of marked, persistent hypercapnia despite reduc- tion of instrumental dead space and increase of respiratory rate. \\ EXPERT OPINION}

\section{Rationale:}

Tidal volume, plateau pressure, and driving pressure are closely related (static compliance $=$ tidal volume $/$ plateau pressure-total PEEP) and all participate in VILI. Mechanical ventilation should limit VILI, thereby limiting mortality. Even if VILI was initially observed on application of a high plateau pressure with a high tidal volume [16], there is less lung injury with the same high plateau pressure when the tidal volume is reduced by means of thoracic stiffness [13], a situation encountered in the very obese.

The LUNG SAFE study reported that plateau pressure was not monitored in $60 \%$ of ventilated ARDS patients and that a non-negligible proportion of patients, although ventilated with a tidal volume below $8 \mathrm{~mL} / \mathrm{kg}$ PBW, had a plateau pressure above $30 \mathrm{cmH}_{2} \mathrm{O}$, especially those with moderate to severe ARDS [2]. An ancillary study of LUNG SAFE has shown that plateau pressure, which can be modified by the intensivist, is strongly and positively correlated with mortality [26]. A high plateau pressure is an independent mortality risk factor, as it reflects either great severity (associated with poor lung compliance) or inadequate mechanical ventilation [27].

The only way to monitor plateau pressure routinely is to ventilate the patient with an end-inspiratory pause, which should not be too long, so as to facilitate any increase in respiratory rate, or too short, so that the respirator can measure the pressure. A pause of $0.2-0.3 \mathrm{~s}$ should be used routinely when adjusting the ventilator.

In a given patient, plateau pressure is an imperfect reflection of lung distension [28]. This is particularly so in patients with abnormal compliance of the chest wall, and in some obese patients. The relation between plateau pressure and mortality or the risk of barotrauma is less clear in these patients [29], which may suggest tolerance of plateau pressure a little above $30 \mathrm{cmH}_{2} \mathrm{O}$, provided that the tidal volume is reduced to limit VILI [13]. In all cases, plateau pressure is no longer associated with barotrauma when it is kept below $30 \mathrm{cmH}_{2} \mathrm{O}$.

Five controlled and randomized studies compared a strategy of low tidal volume and limited plateau pressure with a strategy using higher tidal volume and plateau pressure $[17,18,20,21,30]$. A significant decrease in mortality in the group with limited volume and pressure was observed only in the 2 studies $[20,21]$ where difference in plateau pressure was particularly large between the 2 strategies tested. When these 5 studies are pooled, there is a strong relation between plateau pressure and mortality [31]. In a recent study in 478 patients, a threshold plateau pressure of $29 \mathrm{cmH}_{2} \mathrm{O}$ was identified beyond which hospital mortality increased [32]. Even in patients ventilated with a driving pressure below $19 \mathrm{cmH}_{2} \mathrm{O}$, a plateau pressure strictly below $30 \mathrm{cmH}_{2} \mathrm{O}$ would enable a significant reduction in mortality, a greater effect than that of a driving pressure below $19 \mathrm{cmH}_{2} \mathrm{O}$ when the plateau pressure is already below $30 \mathrm{cmH}_{2} \mathrm{O}$ [32]. These results were validated in the same study in a different cohort of 300 patients [32].

Driving pressure 
R2.3 - Available data do not allow a recommendation to be made regarding respirator settings based solely on limitation of driving pressure. This limitation can be envisaged as a complement to limitation of plateau pressure in some special instances.

\section{NO RECOMMENDATION}

\section{Rationale:}

One study retrospectively evaluated the influence of driving pressure on prognosis by means of a complex statistical analysis of nine randomized controlled studies of ventilation strategy (comparison of different values of tidal volume and PEEP, during ARDS) [33]. The authors concluded that driving pressure was the best predictor of mortality in these studies. Nonetheless, as the authors themselves acknowledge, this was a retrospective study of studies whose main aim was not to examine the usefulness of driving pressure. No randomized study has since corroborated the value of limiting driving pressure. In contrast, the results of the observational study LUNG SAFE $[2,26]$ showed no obvious superiority of driving pressure over plateau pressure as a predictor of the risk of mortality. The same was true when the data of two studies showing improved survival during ARDS (by neuromuscular block and by prone positioning) were combined [34]. Prudence regarding the role of driving pressure is advised, and other studies have even yielded some concerns regarding the validity of this physiological concept. Unlike plateau pressure, which translates dynamic and static lung distension, driving pressure translates dynamic distension. A randomized controlled study of PEEP [35] (which showed that a "higher PEEP" was associated with higher mortality) seems to call into question the predictive value of driving pressure. Indeed, plateau pressure was lower in the group with lower mortality, whereas driving pressure was lower in the group with higher mortality [35].

Analysis of a series of mechanically ventilated ARDS patients presenting acute cor pulmonale [36] suggests that when the plateau pressure is kept sufficiently low $\left(<27 \mathrm{cmH}_{2} \mathrm{O}\right)$, driving pressure is predictive of cor pulmonale and of mortality. A randomized study designed to demonstrate the predictive value of driving pressure should therefore limit plateau pressure to less than $30 \mathrm{cmH}_{2} \mathrm{O}$ or even $28 \mathrm{cmH}_{2} \mathrm{O}$ in the two groups. Given also that tidal volume should be limited to $6 \mathrm{~mL} / \mathrm{kg}$, PEEP is the only ventilator setting that would change. This would therefore amount to comparing two levels of PEEP during ventilation with limited plateau pressure. This is exactly what the EXPRESS study did, and its results were negative [37].
In practical terms, it would be best first to measure and limit plateau pressure, an approach which the LUNG SAFE study [2] has clearly shown is insufficiently used. It is only after limiting plateau pressure sufficiently that we can envisage limiting driving pressure in cases when severely altered lung compliance mandates use of insufficient PEEP to ensure correct oxygenation (for example, in cases when a PEEP of $6-8 \mathrm{cmH}_{2} \mathrm{O}$ and a tidal volume of $6 \mathrm{~mL} / \mathrm{kg}$ would generate a plateau pressure of about $30 \mathrm{cmH}_{2} \mathrm{O}$ in a patient remaining hypoxemic). In this case, it can be useful to reduce driving pressure by further limiting tidal volume, while increasing PEEP, if this maneuver is well tolerated hemodynamically.

\section{Area 3: Alveolar recruitment}

Positive end-expiratory pressure

R3.1.1 - PEEP is an essential component of the management of ARDS and the experts suggest using a value above $5 \mathrm{cmH}_{2} \mathrm{O}$ in all patients presenting with ARDS.

\section{EXPERT OPINION}

R3.1.2 - High PEEP should probably be used in patients with moderate or severe ARDS, but not in patients with mild ARDS.

GRADE $2+$, STRONG AGREEMENT

R3.1.3 - The experts suggest reserving high PEEP for patients in whom it improves oxygenation without marked deterioration of respiratory system compliance or hemodynamic status. PEEP settings should be individualized. EXPERT OPINION

\section{Rationale:}

PEEP is an integral part of the protective ventilation strategy. The expected beneficial effect of high PEEP is optimized alveolar recruitment, which, on the one hand, decreases the intrapulmonary shunt, thus improving arterial oxygenation, and, on the other hand, decreases the amount of lung tissue exposed to alveolar openingclosing, thus reducing the risk of VILI [38, 39]. Conversely, the deleterious effects of high PEEP are increased end-inspiratory lung volume, hence increased risk of volutrauma [13], hemodynamic worsening linked to a decrease in preload, and above all to an increase in right ventricular afterload $[40,41]$. When total PEEP is constant, the effects of intrinsic PEEP are, during ARDS, identical to those of external PEEP [42, 43].

The extent of the beneficial and deleterious effects of high PEEP varies greatly from one patient to another and 
cannot be predicted from the simple clinical data available at the bedside. However, studies using chest CT scans have shown that, on average, the amount of potentially recruitable lung tissue with high PEEP is greater when the $\mathrm{PaO}_{2} / \mathrm{FiO}_{2}$ ratio measured with a low PEEP (5 $\left.\mathrm{cmH}_{2} \mathrm{O}\right)$ is low $[44,45]$.

A post hoc analysis of 2 randomized trials shows that, in patients in whom randomization led to increased PEEP, in-hospital mortality was lower for greater increases in the $\mathrm{PaO}_{2} / \mathrm{FiO}_{2}$ ratio after increase of PEEP [46].

Individually, the effect of high PEEP in terms of recruitment cannot be assessed from changes in respiratory system compliance [45, 47]. No blood gas or respiratory mechanics parameter easily available at the bedside allows quantification of the risk of volutrauma induced by the use of high PEEP. On average, the levels of PEEP used in randomized trials comparing "high" and "moderate" PEEP were, respectively, $15.1 \pm 3.6 \mathrm{cmH}_{2} \mathrm{O}$ and $9.1 \pm 2.7 \mathrm{cmH}_{2} \mathrm{O}$ [24]. Thus, $12 \mathrm{cmH}_{2} \mathrm{O}$ can be considered as the threshold above which PEEP can be qualified as high.

No significant difference in mortality was found in any of the 3 large randomized trials that compared the impact of high and moderate PEEP in ARDS patients ventilated with a tidal volume of $6 \mathrm{~mL} / \mathrm{kg}$ PBW $[37,48,49]$. A metaanalysis of the individual data from patients included in these 3 trials showed that high PEEP was associated with a significant $5 \%$ reduction in hospital mortality in patients with moderate or severe ARDS (34.1\% vs. $39.1 \%$, $p<.05)$, whereas it was associated with greater mortality $(27.2 \%$ vs. $19.4 \%, p=.07)$ in patients with mild ARDS [50].

In patients with moderate or severe ARDS, individualized PEEP setting using end-expiratory transpulmonary pressure did not result in a decrease in mortality compared to PEEP set using a PEEP/FiO ${ }_{2}$ scale [51].

High-frequency oscillation ventilation

\section{R3.2. - High-frequency oscillation ventilation should not be used in ARDS patients. GRADE 1 -, STRONG AGREEMENT}

\section{Rationale:}

High-frequency oscillation ventilation (HFOV) is an unconventional mode of ventilation proposed to improve gas exchange while protecting against VILI using a tidal volume below or equal to the anatomical dead space [52]. Continuous gas flow creates a continuous distending airway pressure $\left(\mathrm{cP}_{\mathrm{aw}}\right)$ so as to recruit the pulmonary parenchyma, whereas the sinusoidal oscillations of a membrane at a high respiratory rate $(3-8 \mathrm{~Hz})$ generate tidal volume. The gas flow and the inflation of a balloon valve allow adjustment of $\mathrm{cP}_{\mathrm{aw}}$, which determines oxygenation proportionally. Tidal volume increases with the amplitude of the membrane movements and decreases when the frequency increases, which explains why $\mathrm{CO}_{2}$ removal is inversely proportional to the frequency used.

Numerous physiological studies have suggested that HFOV is useful in the management of ARDS. Thanks to exchange mechanisms distinct from simple exchange by convection [53], HFOV enables a greater reduction in tidal volume and decreases the amplitude of cyclic variations in transpulmonary pressure, thus allowing the use of a high $\mathrm{cP}_{\mathrm{aw}}$ so as to optimize lung recruitment. By increasing the proportion of parenchyma ventilated, the recruitment induced in HFOV may reduce lung stress and strain, reduce the sheer stress associated with the cyclic opening and closing of unstable alveoli, and limit VILI. Hence, the ventilation characteristics in HFOV make it theoretically ideal in terms of lung protection $[52,54]$.

Several clinical studies have reported that HFOV improves oxygenation in adults with ARDS and refractory hypoxemia in conventional ventilation [55-58]. Three randomized studies reported a tendency to decreased mortality when HFOV was used as an initial mode of ventilation in 58, 148 and 125 ARDS patients, respectively [59-61]. However, the use of excessive tidal volume in the control group limits the value of these studies, which do not allow recommendation of HFOV as the main mode of ventilation for ARDS. Recently, 2 large randomized trials found no benefit of HFOV compared with conventional mechanical ventilation with tidal volume $=6 \mathrm{~mL} / \mathrm{kg}$, limitation of plateau pressure, and PEEP adapted as a function of ARDS severity $[62,63]$. In the OSCILLATE study, an aggressive recruitment strategy in HFOV was even associated with a significant rise in mortality [62]. It is possible that the use of a high $\mathrm{cP}_{\mathrm{aw}}$ induced overdistension without increasing aeration in alveolar collapse or flooding, in particular in patients presenting heterogeneous lesions and a limited percentage of recruitable parenchyma. The use of high pressures may also have induced an increase in right ventricular afterload, right ventricular insufficiency [64], and hemodynamic instability requiring higher doses of vasopressors [62]. With a $\mathrm{CP}_{\mathrm{aw}}$ titration strategy based on the mean alveolar pressure used before the initiation of HFOV and the response in terms of oxygenation, Young et al. found no difference in mortality in the OSCAR study when HFOV was compared with conventional 
mechanical ventilation in ARDS patients [63]. In 2016, the LUNG SAFE study revealed that HFOV was used in $1.2 \%$ of ARDS patients [2].

Several systematic meta-analyses of 5 randomized studies evaluated secondary endpoints, such as gas exchange and the incidence of barotrauma [65-68]. They did not show significant improvement in gas exchange or reduction in barotrauma with HFOV. A recent meta-analysis of individual data suggests that HFOV may improve survival in patients with more severe hypoxemia [66]. The ideal modalities for $\mathrm{cP}_{\mathrm{aw}}$ titration, oscillation frequency, and monitoring of HFOV are poorly defined. In particular, studies are needed to determine whether evaluation of transpulmonary pressure by measurement of esophageal pressure is useful in regulating $\mathrm{CP}_{\mathrm{aw}}$, improving lung recruitment, and avoiding overdistension [69]. Pending the results of an ongoing study that is testing this hypothesis (Clinical Trials.gov NCT02342756), HFOV should be limited to clinical trials in patients with severe ARDS in whom conventional mechanical ventilation has failed despite prone positioning, and should be performed in centers with considerable experience of HFOV.

\section{Recruitment maneuvers}

\section{R3.3 - Recruitment maneuvers should probably not be used routinely in ARDS patients.} GRADE 2-, STRONG AGREEMENT

\section{Rationale:}

In cases of clear derecruitment (endotracheal aspiration, accidental or planned disconnection, intubation...), use can be made of a careful recruitment maneuver. If hypoxemia is refractory $\left(\mathrm{PaO}_{2} / \mathrm{FiO}_{2}<100 \mathrm{mmHg}\right)$ despite optimization of therapy, a recruitment maneuver can be envisaged in the absence of contraindication.

There is no preferred recruitment maneuver. The recommended procedure should last no longer than $10-20 \mathrm{~s}$, and the airway pressure should not exceed $30-40 \mathrm{cmH}_{2} \mathrm{O}$. The recruitment maneuver should be performed with care and should be interrupted if hemodynamic safety is poor.

ARDS patients frequently present pulmonary atelectasis, which decreases the ventilated lung volume, worsens hypoxemia, and increases VILI [70]. The recruitment maneuver, by the application of a transiently high airway pressure, is intended to expand the collapsed lung so as to increase the number of alveolar units participating in gas exchange [71].

Several different maneuvers are used, such as the application of a continuous positive pressure $\left(30-40 \mathrm{cmH}_{2} \mathrm{O}\right)$ for 30-40 s, or the progressive increase of PEEP at constant driving pressure, or the progressive increase of driving pressure at constant PEEP [72-74]. Recruitment maneuvers improve oxygenation and dynamic compliance [75-77]. By application of a high intra-alveolar pressure, they may run the risk of barotrauma related to overdistension of alveoli. By increasing intrathoracic pressure, they can reduce peripheral venous return and right ventricular preload, thereby inducing or worsening hemodynamic instability (particularly in hypovolemic patients) [73].

Recruitment maneuvers were evaluated in 8 controlled randomized studies [21, 35, 49, 78-82] in a total of 2735 patients between 1998 and 2018. The nature of the maneuvers used and the target airway pressures during the maneuver differed substantially between studies. Four of the 8 studies recommended application of a continuous positive airway pressure of $40 \mathrm{cmH}_{2} \mathrm{O}$ for $40 \mathrm{~s}$ [21, 49, $80,82]$. Seven of the 8 studies combined the recruitment maneuver with application of a high PEEP, with the aim of keeping recruited alveoli open [21, 35, 49, 78-81].

In the 8 studies, the use of recruitment maneuvers was not significantly associated with a reduction in mortality at day $28(\mathrm{RR}=0.89-95 \% \mathrm{CI}[0.89-1.07])$. In the only study without co-intervention, recruitment maneuvers were associated with reduced mortality (110 patients, $\mathrm{RR}=0.81-95 \% \mathrm{CI}[0.69-0.95])$. In each of the 7 studies (2625 patients) that gave the $\mathrm{PaO}_{2} / \mathrm{FiO}_{2}$ ratio at day 1 , it was significantly higher in the patients managed using a recruitment maneuver (average of the averages: $205.9 \mathrm{mmHg}$ vs. $158.3 \mathrm{mmHg}$ ) [21, 35, 49, 78-81]. This improvement in $\mathrm{PaO}_{2} / \mathrm{FiO}_{2}$ persisted till day 77 (average of the averages: $231.2 \mathrm{mmHg}$ vs. $195.1 \mathrm{mmHg}$ ) in the same 7 studies (2625 patients) [21, 35, 49, 78-81]. There was no evidence that a recruitment maneuver increased the risk of barotrauma ( $R R=1.25-95 \%$ CI [0.93-1.67]) in 6 studies [21, 35, 49, 78, 80, 81]. In contrast, there was significantly greater worsening of hemodynamic status $(\mathrm{RR}=1.22-95 \% \mathrm{CI}[1.04-1.45])[35,81]$.

There is as yet no proven optimal recruitment maneuver, notably to minimize hemodynamic risk and the risk of barotrauma, while preserving efficacy in terms of lung oxygenation. A recent study [80] opens up a new possibility by adapting the indication for a recruitment maneuver to the CT scan findings (diffuse or focal) in ARDS. The search for a better target population among ARDS patients could provide new information concerning the effect of recruitment maneuvers on mortality.

\section{Area 4: Spontaneous ventilation}

Early and short neuromuscular blockade

R4.1 - A neuromuscular blocking agent should probably be considered in ARDS patients with a $\mathrm{PaO}_{2} / \mathrm{FiO}_{2}$ ratio $<150 \mathrm{mmHg}$ to reduce mortality. The neuromuscular blocking agent should be administered by continuous infusion early 


\section{(within $48 \mathrm{~h}$ after the start of ARDS), for no more than $48 \mathrm{~h}$, with at least daily evaluation. GRADE 2+, STRONG AGREEMENT}

\section{Rationale:}

Three randomized trials tested the effect of the addition of a neuromuscular blocking agent to deep sedation at the initial phase of ARDS [83-85]. The primary outcome of only one of these trials was mortality [85]. A randomized open trial (Reevaluation of Systemic Early Neuromuscular Blockade [ROSE]) methodologically slightly different is currently being analyzed [86]. The ACURASYS study [85] included 339 patients presenting with ARDS with a progression of less than $48 \mathrm{~h}$ and with $\mathrm{PaO}_{2} / \mathrm{FiO}_{2}$ ratio $<150 \mathrm{mmHg}, \mathrm{PEEP} \geq 5 \mathrm{cmH}_{2} \mathrm{O}$, and tidal volume from 6 to $8 \mathrm{~mL} / \mathrm{kg} \mathrm{PBW}$ in a doubleblind, placebo-controlled multicenter study. Patients were included after optimizing invasive mechanical ventilation. Cisatracurium besylate was the neuromuscular blocking agent used. The 90-day mortality did not differ between patients treated with cisatracurium and those treated with placebo $(31.6 \%$ vs. $40.7 \%$, respectively; $p=0.08)$. However, the hazard ratio for 90 -day mortality in the cisatracurium group was 0.68 (95\% CI 0.48-0.98; $p=0.04)$, after adjustment for the $\mathrm{PaO}_{2} / \mathrm{FiO}_{2}$ ratio, plateau pressure, and the Simplified Acute Physiology II score at inclusion [85]. There was improved survival in the patients with a $\mathrm{PaO}_{2} / \mathrm{FiO}_{2}$ ratio $<120 \mathrm{mmHg}$. There were more days alive and free of mechanical ventilation at day 90 in the cisatracurium group (HR 1.41; $p=0.01$ ), and there was no between-group difference in the rate of intensive care unit-acquired paresis [85].

Oxygenation $\left(\mathrm{PaO}_{2} / \mathrm{FiO}_{2}\right)$ increases when neuromuscular blocking agents are used in ARDS patients [83, 84, 87, 88].

In a retrospective study, cisatracurium was not superior to atracurium [89]. In contrast, the duration of mechanical ventilation and the length of ICU stay were slightly but significantly shorter in patients with or at risk of ARDS who were treated with cisatracurium, compared with those treated with vecuronium [90].

The depth of neuromuscular block required is unknown. The ACURASYS study used high dosages of cisatracurium (37 mg/h) [85].

Neuromuscular blocking agents could have beneficial effects in limiting expiratory efforts and Pendelluft effect, and in increasing expiratory transpulmonary pressure [88].

Early spontaneous ventilation

R4.2.1 - Available data do not allow a recommendation to be made regarding a strategy of routine spontaneous ventilation in the acute phase of ARDS.

\section{NO RECOMMENDATION}

R4.2.2 - After the acute phase of ARDS, the experts suggest that ventilation with a pressure mode allowing spontaneous ventilation can be used when ensuring that the tidal volume generated is close to $6 \mathrm{~mL} / \mathrm{kg} \mathrm{PBW}$ and does not exceed $8 \mathrm{~mL} / \mathrm{kg}$ PBW.

\section{EXPERT OPINION}

\section{Rationale:}

The term spontaneous breathing refers to the activity of the respiratory muscles, which is responsible for spontaneous ventilation (SV) in the ventilated patient. The importance of SV depends on the intensity of the breathing efforts and on the impedance of the respiratory system [91]. Spontaneous breathing efforts are present in most ventilated patients, except for those in so-called controlled ventilation who are paralyzed and/or deeply sedated. Spontaneous breathing has very different consequences depending on the mode of ventilation used [92]. During assisted controlled ventilation (either pressure or volume regulated), breathing efforts tend to increase minute ventilation by triggering (via the inspiratory trigger) the ventilator. In this setting, tidal volume can worsen lung injury (concept of patient self-inflicted lung injury) [93]. The interaction can be more complex and responsible for patient-ventilator asynchrony, which in some cases increases tidal volume and may worsen the prognosis [94, 95]. Asynchrony can be limited by adapting the ventilator settings or abolished by neuromuscular blocking agents administration.

With specific pressure-controlled ventilation modes, which does not offer the possibility of inspiratory synchronization (absence of trigger as in airway pressure release ventilation or APRV), breathing efforts generate $\mathrm{SV}$, which is superimposed on mechanical ventilation cycles [91]. Spontaneous breathing efforts have beneficial effects (improved oxygenation, alveolar recruitment, prevention of ventilation-induced diaphragmatic lesions), which should be balanced with deleterious effects (increase in transpulmonary pressure and tidal volume, pendelluft, increased transvascular pressure of the vessels in the lung interstitium, and risk of pulmonary edema) [91]. The benefit-risk balance depends on the severity of respiratory disease and on the level of SV [91]. SV above 30 or $50 \%$ of the total minute ventilation is possibly harmful. If the ventilation defined by the ventilator settings is increased and/or if sedation is too deep, SV 
tends to decline. Conversely, SV increases if the ventilation set on the ventilator is insufficient and/or if sedation is insufficient or in cases of metabolic acidosis [92].

SV can be modulated by sedation and by the level of ventilation delivered by the ventilator.

Nonsynchronized pressure-controlled ventilation (like APRV) favors SV by limiting the asynchrony observed with pressure- or volume-controlled assisted ventilation. SV associated with nonsynchronized pressure-controlled ventilation (like APRV) is associated with increased respiratory effort, which can be detected by variations in airway occlusion pressure.

The beneficial effect of SV on oxygenation and respiratory mechanics has been demonstrated in animal models and confirmed by clinical studies in small numbers of patients. A single-center randomized study comparing SV in APRV versus pressure-controlled ventilation (sedation and neuromuscular block) in 30 mechanically ventilated patients with multiple trauma showed a favorable effect of SV on gas exchange, respiratory mechanics, and the duration of ventilation [96]. The sedation strategy, the large between-group difference in ventilation modalities, and the small number of patients prevent conclusions being drawn regarding the benefit of SV. These methodological obstacles are found in most studies assessing the benefit of SV.

In a recent, randomized single-center trial in 138 patients ventilated for at least $48 \mathrm{~h}$ with a $\mathrm{PaO}_{2} / \mathrm{FiO}_{2}$ ratio $<250 \mathrm{mmHg}$, a protective ventilation strategy (6 $\mathrm{mL} / \mathrm{kg} \mathrm{PBW}$, plateau pressure $<30 \mathrm{cmH}_{2} \mathrm{O}$, PEEP guided by the PEEP-FiO 2 table according to the ARDSNet Protocol) was compared with APRV (tidal volume $6 \mathrm{~mL} / \mathrm{kg}$ PBW, plateau pressure $<30 \mathrm{cmH}_{2} \mathrm{O}$, PEEP $5 \mathrm{cmH}_{2} \mathrm{O}$ ) designed to encourage SV [97]. The sedation strategy was common to the two study arms. The number of days without ventilation at day 28 (principal endpoint) was significantly greater in the APRV arm. Likewise, compliance and oxygenation parameters were significantly improved in APRV, while there was less sedation requirement [97]. Tidal volume and driving pressure were comparable in the two arms, while PEEP and plateau pressure were significantly lower in APRV [97]. The main limitations of this study are that it was singlecenter, there were few patients, and the experience of the "respiratory therapists" who adjusted the APRV settings, which are hard to master [97]. Nonetheless, this study shows the feasibility of a strategy designed to reach modest levels of SV (approximately $30 \%$ of the minute ventilation). The complications were not more frequent in the APRV arm, in which the incidence of pneumothorax was low (4.2\%) [97].

A nonsynchronized mode (like APRV) was compared (crossover, randomized physiological study) with completely or partially synchronized pressure-controlled ventilation [98]. Tidal volume and transpulmonary pressure were significantly lower in cases of nonsynchronization, whereas SV was associated with increased breathing efforts, which could be detected by monitoring airway occlusion pressure [98].

A randomized, controlled multicenter trial has compared the impact of ventilation that systematically encourages SV with assisted controlled ventilation, for a given strategy in the settings of tidal volume, endinspiratory pressure, PEEP, sedation, weaning PEEP, and weaning ventilation. This trial (BiRDS) finished after the inclusion of 700 patients and the results are pending (www.clinicaltrials.gov NCT01862016). The study protocol enabled adaptation of the level of sedation and ventilation so as to achieve the aim of SV.

\section{Area 5: Prone positioning}

\section{R5.1 - Prone positioning should be used in ARDS patients with $\mathrm{PaO}_{2} / \mathrm{FIO}_{2}$ ratio $<150 \mathrm{mmHg}$ to reduce mortality. Sessions of at least 16 consecu- tive hours should be performed. GRADE $1+$, STRONG AGREEMENT}

\section{Rationale:}

The use of prone positioning (PP) during ARDS has been studied in 8 randomized controlled trials, 5 of which were large [10, 45, 99-101] and 3 smaller [102-104]. The most recent meta-analysis concluded that there was no statistically significant difference in mortality between the PP group and the supine position group [105]. This meta-analysis included 3 sensitivity analyses on the role of protective ventilation, the duration of $\mathrm{PP}$, and the severity of hypoxemia at the time of inclusion. When the trial protocol provided for protective mechanical ventilation, there was a non-significant reduction in mortality in favor of PP [105]. This reduction in mortality was significant for PP lasting longer than $12 \mathrm{~h}$, but it not for shorter PP sessions [105]. The reduction in mortality in favor of PP was significant for the most hypoxemic patients with moderate to severe ARDS, but was not significant for less hypoxemic patients (mild ARDS).

The PROSEVA study [10] done in 27 intensive care units showed a significant reduction in mortality in ARDS patients included after a 12 - to 24-h stabilization period with a $\mathrm{PaO}_{2} / \mathrm{FIO}_{2}$ ratio $<150 \mathrm{mmHg}$ associated with PEEP of at least $5 \mathrm{cmH}_{2} \mathrm{O}$, an $\mathrm{FIO}_{2}$ of at least $60 \%$, and tidal volume of $6 \mathrm{~mL} / \mathrm{kg}$ PBW. This confirmed a previous meta-analysis on individual data [106]. In the PROSEVA trial PP group, the patients had on average 4 PP sessions of 17 consecutive hours (the protocol planned 
sessions of at least $16 \mathrm{~h}$ ). PP was continued even in the absence of improved oxygenation.

PP is inexpensive and simple to implement. Optimization of the safety of PP requires that each department has a written procedure and specific training of nursing teams.

\section{Area 6: Extracorporeal gas exchange}

Venovenous extracorporeal membrane oxygenation

\begin{abstract}
R6.1 - Venovenous extracorporeal membrane oxygenation (ECMO) should probably be considered in cases of severe ARDS with $\mathrm{PaO}_{2} /$ $\mathrm{FiO}_{2}<80 \mathrm{mmHg}$ and/or when mechanical ventilation becomes dangerous because of the increase in plateau pressure and despite optimization of ARDS management including high PEEP, neuromuscular blocking agents, and prone positioning. The decision to use ECMO should be evaluated early by means of contact with an expert center.

GRADE 2+, STRONG AGREEMENT
\end{abstract}

\section{Rationale:}

Few studies have assessed the efficacy of ECMO in ARDS. The multicenter CESAR trial [107] randomized 180 patients to transfer to an ECMO center for consideration for ECMO or to conventional ventilatory support. The primary outcome of death and/or severe disability at 6 months was significantly less frequent in the ECMO group, but its interpretation is limited by a large number of control patients who did not receive protective ventilation, and by the fact that $25 \%$ of the patients randomized to the transfer and consideration for ECMO group did not actually receive ECMO [107].

Two retrospective case-controlled studies using propensity score matching $[108,109]$ suggested a benefit of transferring patients with $\mathrm{A}(\mathrm{H} 1 \mathrm{~N} 1)$-related ARDS during the 2009 influenza pandemic to an expert venovenous ECMO referral center.

The randomized EOLIA trial [110] evaluated the effect of early initiation of venovenous ECMO in severe ARDS while avoiding the methodological biases of CESAR. This multicenter trial included 249 patients with severe ARDS on mechanical ventilation for less than 7 days. Patients randomized to the early ECMO group received immediate percutaneous venovenous cannulation while control group patients were managed with protocolized conventional mechanical ventilation. At inclusion, the average $\mathrm{PaO}_{2} / \mathrm{FiO}_{2}$ ratio was 72 , the SOFA score was above 10 , and $75 \%$ of the patients were receiving vasopressors [110]. It should be noted that all control group patients received neuromuscular blocking agents and that $90 \%$ of them had prolonged sessions of PP. Sixty-day mortality was $11 \%$ lower in the ECMO group (35\% versus $46 \%$ ), though the difference did not reach statistical significance $(p=0.09)$ [110]. In contrast, the risk of treatment failure at day 90 (death in the ECMO group, death or crossover to ECMO in the control group) was significantly higher in the control group [110]. Complications associated with ECMO were infrequent, and fewer cases of stroke were observed in the ECMO group. Salvage ECMO was used in $28 \%$ of control patients because of refractory hypoxemia [110]. These patients were extremely ill, and their clinical state deteriorated rapidly in the hours before initiation of ECMO. Their mortality was 57\% and 6 required venoarterial ECMO while undergoing cardiopulmonary resuscitation [110].

Although the frequentist analysis of this study is negative in a strictly statistical sense (60-day mortality, 35\% vs $46 \%, p=0.09$ ), a post hoc Bayesian analysis of EOLIA [111] with various assumptions of prior belief and knowledge about ECMO efficacy in ARDS has shown that the posterior probability of a mortality reduction with ECMO as in the EOLIA trial, was very high (between 88 and 99\%). Furthermore, the EOLIA trial showed that ECMO was safe when provided in high-volume expert centers [110]. It allows the application of ultraprotective ventilation in which pressures and volumes generated by the respirator are drastically reduced, thus protecting the lung from further ventilation-induced lung injury. The EOLIA trial has also demonstrated the relevance and efficacy of hospital networks to safely retrieve on ECMO the most severely ill patients 24/7 with an ECMO mobile team to an ECMO referral center [110].

Low-flow extracorporeal $\mathrm{CO}_{2}$ removal

\section{R6.2 - Available data do not allow a recommen- dation to be made concerning the use of low- flow extracorporeal $\mathrm{CO}_{2}$ removal during ARDS. NO RECOMMENDATION}

\section{Rationale:}

Arteriovenous or venovenous low-flow extracorporeal $\mathrm{CO}_{2}$ removal $\left(\mathrm{ECCO}_{2} \mathrm{R}\right)$ allows so-called "ultraprotective" ventilation strategies (tidal volume $<6 \mathrm{~mL} / \mathrm{kg} \mathrm{PBW}$ and decrease in plateau and driving pressures and in respiratory rate) during ARDS, by controlling hypercapnia induced by the reduction in minute ventilation. Ten studies tested this approach [112-121], but the overall level of proof is very low. In the only recent randomized controlled trial that included 79 patients, the numbers of ventilator-free days at day 60 were not different between control and $\mathrm{ECCO}_{2} \mathrm{R}$ groups, although a post hoc analysis suggested a benefit of $\mathrm{ECCO}_{2} \mathrm{R}$ for the most hypoxemic patients $\left(\mathrm{PaO}_{2} / \mathrm{FiO}_{2}<150 \mathrm{mmHg}\right.$ at inclusion $)$ [113]. 
Observational studies suggest that hypercapnia has an unfavorable prognostic effect in ARDS; it is associated in multivariate analysis with pulmonary vascular and right ventricular dysfunction [36] and with mortality [19]. $\mathrm{ECCO}_{2} \mathrm{R}$ can decrease $\mathrm{PaCO}_{2}$ in hypercapnic ARDS patients receiving "conventional" protective ventilation (tidal volume about $6 \mathrm{~mL} / \mathrm{kg} \mathrm{PBW}$ ) [112, 115, 116, $122-124]$ or ultraprotective ventilation $[117,120]$. Nonetheless, the positive effect of the control of hypercapnia on morbidity and mortality has yet to be demonstrated in ARDS.

The effect of $\mathrm{ECCO}_{2} \mathrm{R}$ on $\mathrm{PaO}_{2}$ in ARDS patients is inconstant, some studies reporting an improvement [119-122] and many others no significant effect [112, $114,115,117,118,124,125]$. Because $\mathrm{ECCO}_{2} \mathrm{R}$ only provides marginal blood oxygenation, venovenous ECMO is required in the most hypoxemic patients. Lastly, $\mathrm{ECCO}_{2} \mathrm{R}$ is associated with a wide range of complications (bleeding, thrombosis, and infections) that should be balanced against its potential benefits [126].

\section{Area 7: Inhaled nitric oxide}

R7.1 - The experts suggest that inhaled nitric oxide can be used in cases of ARDS with deep hypoxemia despite the implementation of a protective ventilation strategy and prone positioning, and before envisaging use of venovenous ECMO.

EXPERT OPINION

\section{Rationale:}

Initially considered as a pollutant, nitric oxide (NO) is a ubiquitous, odorless and colorless gas whose properties were demonstrated by Furchgott, Ignarro, Murad, and Moncada in work that was rewarded by a Nobel Prize [127]. Produced by endothelial cells, NO induces vasodilation by increasing the level of cyclic GMP in smooth muscle cells. Depending on its concentration, NO, in addition to its vasomotor properties, produces numerous potentially interesting pro- or anti-inflammatory effects in the setting of ARDS [128]. Notably, it attenuates leukocyte activation and inflammatory responses, reduces platelet aggregation, has a bronchodilator effect, and facilitates the production of surfactant.

When inhaled, NO diffuses into ventilated areas where it induces vasodilation before rapidly binding to hemoglobin by a reaction with the ferrous and ferric ion of heme to form nitrosylated hemoglobin [128]. By reacting with oxyhemoglobin, the predominant form in the lung, NO forms methemoglobin and nitrates and does not result in systemic vasodilation. Approximately $70 \%$ of inhaled NO (iNO) is eliminated in the form of nitrate in urine [129]. iNO is a selective pulmonary arterial vasodilator likely to improve gas exchange by reducing the shunt and to control pulmonary arterial hypertension and right ventricular insufficiency, which has an unfavorable prognosis in ARDS [130, 131]. In addition, its effects on platelets and leukocytes could prove of therapeutic value in ARDS.

Inhalation of NO dilates the pulmonary vessels in ventilated areas and improves the ventilation-perfusion ratio by preferentially redistributing the blood flow to these areas. Eleven randomized trials report an improvement in the $\mathrm{PaO}_{2} / \mathrm{FiO}_{2}$ ratio after $24 \mathrm{~h}$ of treatment [132]. However, this improvement is transient and only an analysis based on 4 trials indicates improvement that persists after $96 \mathrm{~h}$ of treatment [132]. Note that the response is greater if there is pulmonary arterial hypertension, that the concentrations likely to improve oxygenation are generally below 5 parts per million (ppm) [133], and that concentrations above $10 \mathrm{ppm}$ are sometimes associated with a worsening of the $\mathrm{PaO}_{2} / \mathrm{FiO}_{2}$ ratio, possibly because of the diffusion of NO into unventilated areas [134].

To date, 8 randomized studies in a total of 1025 adults with ARDS, including at least 10 treated with iNO, evaluated the impact of this treatment on mortality [133, 135-140]. None of these studies found significant improvement in survival at 28 days or long term. Analysis of available randomized studies reveals that iNO does not change the duration of mechanical ventilation, the time spent in intensive care, or the onset of barotrauma complications. Published between 1997 and 2004, most of these studies have a relatively modest risk of bias, but they suffer from a certain number of methodological problems that complicate the interpretation. Most of these studies lack power and evaluate the response of heterogenous patients in terms of the etiology of ARDS. The modalities of administration (concentration, duration, evaluation of the response, weaning) and of monitoring were insufficiently defined and varied greatly from one study to another. Also, these studies were conducted before the generalization of protective ventilation strategies for ARDS. In the most recent study, in 385 patients, the tidal volume used in the 2 groups was $10 \mathrm{~mL} / \mathrm{kg}$ [139]. Compliance with a protective ventilation strategy is not reported in any study, and there were no protocols for mechanical ventilation weaning or for optimization of sedation in these studies. It is therefore difficult to draw definitive conclusions as to any benefit of iNO in ARDS.

Given a quite favorable benefit-risk ratio, the physiological effects of iNO on the reduction in the intrapulmonary shunt, and the improvement of gas exchange, right ventricular performance, and cardiac flow may justify its use in severe ARDS when PP and optimization of mechanical ventilation do not correct hypoxemia. Data 


\section{Table 2 Summary of guidelines}

Recommendation

The experts suggest that the efficacy and safety of all ventilation parameters and therapeutics associated with ARDS management should be evaluated at least every $24 \mathrm{~h}$

Tidal volume adjustment

R2.1.1

Plateau pressure

Driving pressure

Positive end-expiratory pressure

R3.1.2

High-frequency oscillation ventilation

R3.2

Recruitment maneuvers

R3.3

Early and short neuromuscular blockade R4.1

Early spontaneous ventilation

R4.2.2

Prone positioning

R5. 1
A tidal volume around $6 \mathrm{~mL} / \mathrm{kg}$ of predicted body weight (PBW) should be used as a first approach in patients with recognized ARDS, in the absence of severe metabolic acidosis, including those with mild ARDS, to reduce mortality

The experts suggest a similar approach for all patients on invasive mechanical ventilation and under sedation in ICU, given the high rate of failure to recognize ARDS and the importance of rapidly implementing pulmonary protection

Once tidal volume is set to around $6 \mathrm{~mL} / \mathrm{kg}$ predicted body weight, plateau pressure should be monitored continuously and should not exceed $30 \mathrm{cmH}_{2} \mathrm{O}$ to reduce mortality

The experts suggest that tidal volume should not be increased when the plateau pressure is well below $30 \mathrm{cmH}_{2} \mathrm{O}$, except in cases of marked, persistent hypercapnia despite reduction in instrumental dead space and increase of respiratory rate

Available data do not allow a recommendation to be made regarding respican be envisaged as a complement to limitation of plateau pressure in some special instances

PEEP is an essential component of the management of ARDS and the experts suggest using a value above $5 \mathrm{cmH}_{2} \mathrm{O}$ in all patients presenting with ARDS

High PEEP should probably be used in patients with moderate or severe ARDS, but not in patients with mild ARDS

The experts suggest reserving high PEEP for patients in whom it improves oxygenation without marked deterioration of respiratory system compliance or hemodynamic status. PEEP settings should be individualized

High-frequency oscillation ventilation should not be used in ARDS patients

Recruitment maneuvers should probably not be used routinely in ARDS patients

A neuromuscular blocking agent should probably be considered in ARDS patients with a $\mathrm{PaO}_{2} / \mathrm{FiO}_{2}$ ratio $<150 \mathrm{mmHg}$ to reduce mortality. The neuromuscular blocking agent should be administered by continuous infusion early (within $48 \mathrm{~h}$ after the start of ARDS), for no more than $48 \mathrm{~h}$, with at least daily evaluation

Available data do not allow a recommendation to be made regarding a strategy of routine spontaneous ventilation in the acute phase of ARDS

After the acute phase of ARDS, the experts suggest that ventilation with a pressure mode allowing spontaneous ventilation can be used when ensuring that the tidal volume generated is close to $6 \mathrm{~mL} / \mathrm{kg}$ PBW and does not exceed $8 \mathrm{~mL} / \mathrm{kg}$ PBW

Prone positioning should be used in ARDS patients with $\mathrm{PaO}_{2} / \mathrm{FIO}_{2}$ ratio $<150 \mathrm{mmHg}$ to reduce mortality. Sessions of at least 16 consecutive hours should be performed rator settings based solely on limitation of driving pressure. This limitation
Level of proof

Expert opinion

Grade $1+$

Expert opinion

Grade $1+$

Expert opinion

No recommendation

Expert opinion

Grade $2+$

Expert opinion

Grade 1 -

Grade 2 -

Grade $2+$

No recommendation

Expert opinion

Grade $1+$ 
Table 2 (continued)

\begin{tabular}{|c|c|c|}
\hline & Recommendation & Level of proof \\
\hline \multicolumn{3}{|c|}{ Venovenous extracorporeal membrane oxygenation } \\
\hline R6.1 & $\begin{array}{l}\text { Venovenous extracorporeal membrane oxygenation (ECMO) should prob- } \\
\text { ably be considered in cases of severe ARDS with } \mathrm{PaO}_{2} / \mathrm{FiO}_{2}<80 \mathrm{mmHg} \\
\text { and/or when mechanical ventilation becomes dangerous because of the } \\
\text { increase in plateau pressure and despite optimization of ARDS manage- } \\
\text { ment including high PEEP, neuromuscular blocking agents, and prone } \\
\text { positioning. The decision to use ECMO should be evaluated early by means } \\
\text { of contact with an expert center }\end{array}$ & Grade $2+$ \\
\hline \multicolumn{3}{|c|}{ Low-flow extracorporeal $\mathrm{CO}_{2}$ removal } \\
\hline R6.2 & $\begin{array}{l}\text { Available data do not allow a recommendation to be made concerning the } \\
\text { use of low-flow extracorporeal } \mathrm{CO}_{2} \text { removal during ARDS }\end{array}$ & No recommendation \\
\hline \multicolumn{3}{|c|}{ Inhaled nitrogen monoxide } \\
\hline R7.1 & $\begin{array}{l}\text { The experts suggest that inhaled nitric oxide can be used in cases of } \\
\text { ARDS with deep hypoxemia, despite the implementation of a protective } \\
\text { ventilation strategy and prone positioning and before envisaging use of } \\
\text { venovenous ECMO }\end{array}$ & Expert opinion \\
\hline
\end{tabular}

from physiological studies and the main clinical trials suggest that iNO has a good safety profile and that its potential adverse effects, notably methemoglobinemia, inhibition of platelet aggregation, and systemic vasodilation, are not clinically significant if a few precautions are observed [135, 141-143]. In the presence of oxygen, NO is transformed into nitrite $\left(\mathrm{NO}_{2}\right)$ and then nitrate $\left(\mathrm{NO}_{3}\right)$. However, if inhaled with a high $\mathrm{FiO}_{2}$, $\mathrm{NO}$ together with reactive oxygen species can form potentially toxic molecules, in particular peroxynitrite $\left(\mathrm{ONOO}^{-}\right)$[141]. NO can also bind to amino acids such as tyrosine and engender posttranslational changes in proteins, such as nitrosation, nitrosylation, and nitration. Furthermore, a risk of renal toxicity has been described in a clinical trial [136] and in a recent meta-analysis [132]. A systematic review of trials reveals that the risk of renal toxicity seems to be limited to ARDS patients exposed to high iNO concentrations for prolonged periods [144]. To limit the risk of complications with iNO, it is appropriate to: (1) minimize exposure by using systems of administration that enable inhalation synchronized with inspiratory flow and precise monitoring of the concentrations of NO and NOx, (2) use the minimum effective concentration to improve the $\mathrm{PaO}_{2} / \mathrm{FiO}_{2}$ ratio and not maintain iNO in a nonresponsive patient, (3) reevaluate the response and the required dosage daily. In cases of prolonged use, methemoglobinemia should also be monitored. Lastly, weaning from iNO should be progressive so as to limit the risk of a sudden increase in pulmonary arterial pressure.

\section{Abbreviations}

APRV: airway pressure release ventilation; ARDS: acute respiratory distress syndrome; $\mathrm{CP}$ aw: continuous distending airway pressure; $\mathrm{ECMO}$ : extracorporeal membrane oxygenation; $\mathrm{ECCO}_{2} \mathrm{R}$ : extracorporeal $\mathrm{CO}_{2}$ removal; GRADE: Grade of Recommendation Assessment, Development and Evaluation; HFOV: high-frequency oscillation ventilation; ICU: intensive care unit; NO: nitric oxide; PBW: predicted body weight; PEEP: positive end-expiratory pressure; PICO: Patient Intervention Comparison Outcome; PP: prone position; PPM: parts per million; SRLF: Société de Réanimation de Langue Française; SV: spontaneous ventilation; VILI: ventilator-induced lung injury.

\section{Acknowledgements}

Guidelines reviewed and endorsed by the SRLF (20/12/2018) boards.

\section{Authors' contributions}

LP proposed the elaboration of this recommendation and manuscript in agreement with the "Société de Réanimation de Langue Française" and wrote introduction; HF wrote the methodology section and gave the final version with the final presentation. CA and DR contributed to elaborate recommendations and to write the rationale of area 1 (evaluation of ARDS management) and elaborated figures. $L B, A V B$, and DD contributed to elaborate recommendations and to write the rationale of area 2 (Tidal volume management). AM, JDC, and SJ contributed to elaborate recommendations and to write the rationale of area 3 (alveolar recruitment). JMF and JCR contributed to elaborate recommendations and to write the rationale of area 4 (spontaneous ventilation). CG contributed to elaborate recommendations and to write the rationale of area 5 (prone positioning). AC and $\mathrm{AMD}$ contributed to elaborate recommendations and to write the rationale of area 6 (extracorporeal gas exchange). JDC contributed to elaborate recommendations and to write the rationale of area 7 (inhaled nitric oxide). LP and HF drafted the manuscript. All authors read and approved the final manuscript.

\section{Funding}

This work was financially supported by the Société de Réanimation de Langue Française (SRLF).

Availability of data and materials

Not applicable.

Ethics approval and consent to participate

Not applicable.

\section{Consent for publication}

Not applicable.

\section{Competing interests}

Laurent Brochard: Philips; General Electric; Fisher Paykel; Air Liquide; Sentec; Medtronic Covidien. Jean-Daniel Chiche: General Electric Healthcare. Alain Combes: Maquet Getinge; Baxter. Samir Jaber: Drager; Fisher Paykel; Xenios. Armand Mekontso-Dessap: Air Liquide; Baxter; Fischer Paykel; Philips. Laurent Papazian: Air Liquide MS; MSD; Drager; Maquet; Medtronic. Jean-Christophe M. 
Richard: Air Liquide Medical System; Vygon; Covidien; General Electric. Damien Roux: Astellas. Antoine Vieillard-Baron: GSK. The remaining authors declare no competing interests.

\section{Author details}

1 Service de Médecine Intensive - Réanimation, Hôpital Nord, Chemin des Bourrely, 13015 Marseille, France. ${ }^{2}$ Medical Intensive Care Unit, Centre Hospitalier Régional et Universitaire de Brest, site La Cavale Blanche, Bvd Tanguy Prigent, 29609 Brest Cedex, France. ${ }^{3}$ Interdepartmental Division of Critical Care Medicine, University of Toronto, Toronto, Canada. ${ }^{4}$ Service de Médecine Intensive - Réanimation, Hôpital Cochin, Hôpitaux Universitaires Paris-Centre, Assistance Publique - Hôpitaux de Paris, 27 Rue du Faubourg Saint-Jacques, 75014 Paris, France. ${ }^{5}$ Service de Réanimation, Institut de Cardiologie, Groupe Hospitalier Pitié- Salpêtrière, Assistance Publique-Hôpitaux de Paris, 47, boulevard de l'Hôpital, 75013 Paris, France. ${ }^{6}$ Intensive Care Unit, Louis Mourier Hospital, AP-HP, 178 Rue des Renouillers, 92700 Colombes, France. ${ }^{7}$ Service de Réanimation Médicale, Hôpital De La Croix Rousse, Hospices Civils de Lyon, 103 Grande Rue de la Croix Rousse, 69004 Lyon, France. ${ }^{8}$ Department of Anesthesiology and Intensive Care (DAR B), Saint Eloi University Hospital, Montpellier, France. ${ }^{9}$ Service de Réanimation Médicale, Hôpitaux Universitaires HenriMondor, AP-HP, DHU A-TVB, 94010 Créteil, France. ${ }^{10}$ Medical Intensive Care Department, Angers University Hospital, 4, rue Larrey, 49933 Angers Cedex, France. ${ }^{11}$ Emergency Department, General Hospital of Annecy, Annecy, France. ${ }^{12}$ Hospital Ambroise Paré, Assistance Publique-Hôpitaux de Paris, Boulogne, France. ${ }^{13}$ Service de Médecine Intensive - Réanimation, Centre Hospitalier Intercommunal Robert Ballanger, 93602 Aulnay-sous-Bois, France.

\section{Received: 15 April 2019 Accepted: 27 May 2019}

Published online: 13 June 2019

\section{References}

1. Ranieri VM, Rubenfeld GD, Thompson BT, Ferguson ND, Caldwell E, Fan $\mathrm{E}$, et al. Acute respiratory distress syndrome: the Berlin Definition. JAMA. 2012;307(23):2526-33.

2. Bellani G, Laffey JG, Pham T, Fan E, Brochard L, Esteban A, et al. Epidemiology, patterns of care, and mortality for patients with acute respiratory distress syndrome in intensive care units in 50 countries. JAMA. 2016;315(8):788-800.

3. Li G, Malinchoc M, Cartin-Ceba R, Venkata CV, Kor DJ, Peters SG, et al. Eight-year trend of acute respiratory distress syndrome: a populationbased study in Olmsted County, Minnesota. Am J Respir Crit Care Med. 2011;183(1):59-66.

4. Villar J, Blanco J, Anon JM, Santos-Bouza A, Blanch L, Ambros A, et al. The ALIEN study: incidence and outcome of acute respiratory distress syndrome in the era of lung protective ventilation. Intensive Care Med. 2011;37(12):1932-41.

5. Herridge MS, Tansey CM, Matte A, Tomlinson G, Diaz-Granados N, Cooper A, et al. Functional disability 5 years after acute respiratory distress syndrome. N Engl J Med. 2011;364(14):1293-304.

6. De Prost N, Dreyfuss D. How to prevent ventilator-induced lung injury? Minerva Anestesiol. 2012;78(9):1054-66.

7. Fan E, Brodie D, Slutsky AS. Acute respiratory distress syndrome: advances in diagnosis and treatment. JAMA. 2018;319(7):698-710.

8. Gattinoni L, Marini JJ, Collino F, Maiolo G, Rapetti F, Tonetti T, et al. The future of mechanical ventilation: lessons from the present and the past. Crit Care. 2017;21(1):183.

9. Cressoni M, Cadringher P, Chiurazzi C, Amini M, Gallazzi E, Marino A, et al. Lung inhomogeneity in patients with acute respiratory distress syndrome. Am J Respir Crit Care Med. 2014;189(2):149-58.

10. Guerin C, Reignier J, Richard JC, Beuret P, Gacouin A, Boulain T, et al. Prone positioning in severe acute respiratory distress syndrome. N Engl J Med. 2013;368(23):2159-68.

11. Chen L, Chen GQ, Shore K, Shklar O, Martins C, Devenyi B, et al. Implementing a bedside assessment of respiratory mechanics in patients with acute respiratory distress syndrome. Crit Care. 2017;21(1):84.

12. Ely EW, Baker AM, Evans GW, Haponik EF. The prognostic significance of passing a daily screen of weaning parameters. Intensive Care Med. 1999;25(6):581-7.
13. Dreyfuss D, Saumon G. Ventilator-induced lung injury: lessons from experimental studies. Am J Respir Crit Care Med. 1998;157(1):294-323.

14. Hickling KG, Henderson SJ, Jackson R. Low mortality associated with low volume pressure limited ventilation with permissive hypercapnia in severe adult respiratory distress syndrome. Intensive Care Med. 1990;16(6):372-7.

15. Slutsky AS. Mechanical ventilation. American College of Chest Physicians' Consensus Conference. Chest. 1993;104(6):1833-59.

16. Webb HH, Tierney DF. Experimental pulmonary edema due to intermittent positive pressure ventilation with high inflation pressures. Protection by positive end-expiratory pressure. Am Rev Respir Dis. 1974;110(5):556-65.

17. Brochard L, Roudot-Thoraval F, Roupie E, Delclaux C, Chastre J, Fernandez-Mondejar E, et al. Tidal volume reduction for prevention of ventilator-induced lung injury in acute respiratory distress syndrome. The Multicenter Trail Group on Tidal Volume reduction in ARDS. Am J Respir Crit Care Med. 1998;158(6):1831-8.

18. Brower RG, Shanholtz CB, Fessler HE, Shade DM, White P Jr, Wiener $C M$, et al. Prospective, randomized, controlled clinical trial comparing traditional versus reduced tidal volume ventilation in acute respiratory distress syndrome patients. Crit Care Med. 1999;27(8):1492-8.

19. Nin N, Muriel A, Penuelas O, Brochard L, Lorente JA, Ferguson ND, et al. Severe hypercapnia and outcome of mechanically ventilated patients with moderate or severe acute respiratory distress syndrome. Intensive Care Med. 2017;43(2):200-8.

20. Brower RG, Matthay MA, Morris A, Schoenfeld D, Thompson BT, Wheeler A. Ventilation with lower tidal volumes as compared with traditional tidal volumes for acute lung injury and the acute respiratory distress syndrome. N Engl J Med. 2000;342(18):1301-8.

21. Amato MB, Barbas CS, Medeiros DM, Magaldi RB, Schettino GP, Lorenzi-Filho $\mathrm{G}$, et al. Effect of a protective-ventilation strategy on mortality in the acute respiratory distress syndrome. N Engl J Med. 1998;338(6):347-54.

22. Villar J, Kacmarek RM, Perez-Mendez L, Aguirre-Jaime A. A high positive end-expiratory pressure, low tidal volume ventilatory strategy improves outcome in persistent acute respiratory distress syndrome: a randomized, controlled trial. Crit Care Med. 2006;34(5):1311-8.

23. Burns KE, Adhikari NK, Slutsky AS, Guyatt GH, Villar J, Zhang H, et al. Pressure and volume limited ventilation for the ventilatory management of patients with acute lung injury: a systematic review and meta-analysis. PLOS ONE. 2011;6(1):e14623.

24. Walkey AJ, Goligher EC, Del Sorbo L, Hodgson CL, Adhikari NKJ, Wunsch $\mathrm{H}$, et al. Low tidal volume versus non-volume-limited strategies for patients with acute respiratory distress syndrome. A systematic review and meta-analysis. Ann Am Thorac Soc. 2017;14(Supplement_4):S271-9.

25. Needham DM, Yang T, Dinglas VD, Mendez-Tellez PA, Shanholtz C, Sevransky JE, et al. Timing of low tidal volume ventilation and intensive care unit mortality in acute respiratory distress syndrome. A prospective cohort study. Am J Respir Crit Care Med. 2015;191(2):177-85.

26. Laffey JG, Bellani G, Pham T, Fan E, Madotto F, Bajwa EK, et al. Potentially modifiable factors contributing to outcome from acute respiratory distress syndrome: the LUNG SAFE study. Intensive Care Med. 2016;42(12):1865-76.

27. Villar J, Perez-Mendez L, Basaldua S, Blanco J, Aguilar G, Toral D, et al. A risk tertiles model for predicting mortality in patients with acute respiratory distress syndrome: age, plateau pressure, and $\mathrm{P}(\mathrm{aO}(2)) / \mathrm{F}(\mathrm{IO}(2))$ at ARDS onset can predict mortality. Respir Care. 2011;56(4):420-8.

28. Chiumello D, Carlesso E, Cadringher P, Caironi P, Valenza F, Polli F, et al. Lung stress and strain during mechanical ventilation for acute respiratory distress syndrome. Am J Respir Crit Care Med. 2008;178(4):346-55.

29. De Jong A, Cossic J, Verzilli D, Monet C, Carr J, Conseil M, et al. Impact of the driving pressure on mortality in obese and non-obese ARDS patients: a retrospective study of 362 cases. Intensive Care Med. 2018;44(7):1106-14.

30. Stewart TE, Meade MO, Cook DJ, Granton JT, Hodder RV, Lapinsky SE, et al. Evaluation of a ventilation strategy to prevent barotrauma in patients at high risk for acute respiratory distress syndrome. Pressure- and volume-limited ventilation strategy group. N Engl J Med. 1998;338(6):355-61. 
31. Hager DN, Krishnan JA, Hayden DL, Brower RG, Network ACT. Tidal volume reduction in patients with acute lung injury when plateau pressures are not high. Am J Respir Crit Care Med. 2005;172(10):1241-5.

32. Villar J, Martin-Rodriguez C, Dominguez-Berrot AM, Fernandez L, Ferrando C, Soler JA, et al. A quantile analysis of plateau and driving pressures: effects on mortality in patients with acute respiratory distress syndrome receiving lung-protective ventilation. Crit Care Med. 2017;45(5):843-50.

33. Amato MB, Meade MO, Slutsky AS, Brochard L, Costa EL, Schoenfeld DA, et al. Driving pressure and survival in the acute respiratory distress syndrome. N Engl J Med. 2015;372(8):747-55.

34. Guerin C, Papazian L, Reignier J, Ayzac L, Loundou A, Forel JM, et al. Effect of driving pressure on mortality in ARDS patients during lung protective mechanical ventilation in two randomized controlled trials. Crit Care. 2016;20(1):384

35. Cavalcanti AB, Suzumura EA, Laranjeira LN, Paisani DM, Damiani LP, et al. Effect of lung recruitment and titrated positive end-expiratory pressure (PEEP) vs low peep on mortality in patients with acute respiratory distress syndrome: a randomized clinical trial. JAMA. 2017;318(14):1335-45

36. Mekontso Dessap A, Boissier F, Charron C, Begot E, Repesse X, Legras A, et al. Acute cor pulmonale during protective ventilation for acute respiratory distress syndrome: prevalence, predictors, and clinical impact. Intensive Care Med. 2016;42(5):862-70.

37. Mercat A, Richard JC, Vielle B, Jaber S, Osman D, Diehl JL, et al. Positive end-expiratory pressure setting in adults with acute lung injury and acute respiratory distress syndrome: a randomized controlled trial. JAMA. 2008;299(6):646-55.

38. Sahetya SK, Goligher EC, Brower RG. Fifty years of research in ARDS. Setting positive end-expiratory pressure in acute respiratory distress syndrome. Am J Respir Crit Care Med. 2017;195(11):1429-38.

39. Slutsky AS, Ranieri VM. Ventilator-induced lung injury. N Engl J Med. 2013;369(22):2126-36.

40. Fougeres E, Teboul JL, Richard C, Osman D, Chemla D, Monnet X. Hemodynamic impact of a positive end-expiratory pressure setting in acute respiratory distress syndrome: importance of the volume status. Crit Care Med. 2010;38(3):802-7.

41. Schmitt JM, Vieillard-Baron A, Augarde R, Prin S, Page B, Jardin F. Positive end-expiratory pressure titration in acute respiratory distress syndrome patients: impact on right ventricular outflow impedance evaluated by pulmonary artery Doppler flow velocity measurements. Crit Care Med. 2001;29(6):1154-8.

42. Lessard MR, Guerot E, Lorino H, Lemaire F, Brochard L. Effects of pressure-controlled with different I: E ratios versus volume-controlled ventilation on respiratory mechanics, gas exchange, and hemodynamics in patients with adult respiratory distress syndrome. Anesthesiology. 1994:80(5):983-91.

43. Mercat A, Graini L, Teboul JL, Lenique F, Richard C. Cardiorespiratory effects of pressure-controlled ventilation with and without inverse ratio in the adult respiratory distress syndrome. Chest. 1993;104(3):871-5

44. Caironi $\mathrm{P}$, Carlesso E, Cressoni M, Chiumello D, Moerer O, Chiurazzi C, et al. Lung recruitability is better estimated according to the Berlin definition of acute respiratory distress syndrome at standard $5 \mathrm{~cm} \mathrm{H}_{2} \mathrm{O}$ rather than higher positive end-expiratory pressure: a retrospective cohort study. Crit Care Med. 2015;43(4):781-90.

45. Gattinoni L, Caironi P, Cressoni M, Chiumello D, Ranieri VM, Quintel M, et al. Lung recruitment in patients with the acute respiratory distress syndrome. N Engl J Med. 2006;354(17):1775-86.

46. Goligher EC, Kavanagh BP, Rubenfeld GD, Adhikari NK, Pinto R, Fan $E$, et al. Oxygenation response to positive end-expiratory pressure predicts mortality in acute respiratory distress syndrome. A secondary analysis of the LOVS and ExPress trials. Am J Respir Crit Care Med. 2014;190(1):70-6.

47. Maggiore SM, Jonson B, Richard JC, Jaber S, Lemaire F, Brochard L. Alveolar derecruitment at decremental positive end-expiratory pressure levels in acute lung injury: comparison with the lower inflection point, oxygenation, and compliance. Am J Respir Crit Care Med. 2001;164(5):795-801.

48. Brower RG, Lanken PN, MacIntyre N, Matthay MA, Morris A, Ancukiewicz $M$, et al. Higher versus lower positive end-expiratory pressures in patients with the acute respiratory distress syndrome. N Engl J Med. 2004;351(4):327-36.

49. Meade MO, Cook DJ, Guyatt GH, Slutsky AS, Arabi YM, Cooper DJ, et al Ventilation strategy using low tidal volumes, recruitment maneuvers, and high positive end-expiratory pressure for acute lung injury and acute respiratory distress syndrome: a randomized controlled trial. JAMA. 2008;299(6):637-45.

50. Briel M, Meade M, Mercat A, Brower RG, Talmor D, Walter SD, et al. Higher vs lower positive end-expiratory pressure in patients with acute lung injury and acute respiratory distress syndrome: systematic review and meta-analysis. JAMA. 2010;303(9):865-73.

51. Cavalcanti AB, Suzumura EA, Laranjeira LN, Paisani DM, Damiani LP, Guimaraes HP, et al. Effect of lung recruitment and titrated positive endexpiratory pressure (PEEP) vs low PEEP on mortality in patients with acute respiratory distress syndrome: a randomized clinical trial. JAMA. 2017;318(14):1335-45.

52. Ferguson ND, Villar J, Slutsky AS. Understanding high-frequency oscillation: lessons from the animal kingdom. Intensive Care Med. 2007;33(8):1316-8.

53. Sklar MC, Fan E, Goligher EC. High-frequency oscillatory ventilation in adults with ARDS: past, present, and future. Chest. 2017;152(6):1306-17.

54. Adhikari NK, Bashir A, Lamontagne F, Mehta S, Ferguson ND, Zhou Q, et al. High-frequency oscillation in adults: a utilization review. Crit Care Med. 2011;39(12):2631-44.

55. Camporota L, Sherry T, Smith J, Lei K, McLuckie A, Beale R. Physiological predictors of survival during high-frequency oscillatory ventilation in adults with acute respiratory distress syndrome. Crit Care. 2013;17(2):R40.

56. Fessler HE, Hager DN, Brower RG. Feasibility of very high-frequency ventilation in adults with acute respiratory distress syndrome. Crit Care Med. 2008;36(4):1043-8.

57. Fort P, Farmer C, Westerman J, Johannigman J, Beninati W, Dolan S, et al. High-frequency oscillatory ventilation for adult respiratory distress syndrome-a pilot study. Crit Care Med. 1997;25(6):937-47.

58. Mehta S, Granton J, MacDonald RJ, Bowman D, Matte-Martyn A, Bachman T, et al. High-frequency oscillatory ventilation in adults: the Toronto experience. Chest. 2004;126(2):518-27.

59. Bollen CW, van Well GT, Sherry T, Beale RJ, Shah S, Findlay G, et al. High frequency oscillatory ventilation compared with conventional mechanical ventilation in adult respiratory distress syndrome: a randomized controlled trial [ISRCTN24242669]. Crit Care. 2005;9(4):R430-9.

60. Derdak S, Mehta S, Stewart TE, Smith T, Rogers M, Buchman TG, et al. High-frequency oscillatory ventilation for acute respiratory distress syndrome in adults: a randomized, controlled trial. Am J Respir Crit Care Med. 2002;166(6):801-8

61. Mentzelopoulos SD, Malachias S, Kokkoris S, Roussos C, Zakynthinos SG Comparison of high-frequency oscillation and tracheal gas insufflation versus standard high-frequency oscillation at two levels of tracheal pressure. Intensive Care Med. 2010;36(5):810-6.

62. Ferguson ND, Cook DJ, Guyatt GH, Mehta S, Hand L, Austin P, et al. High-frequency oscillation in early acute respiratory distress syndrome. N Engl J Med. 2013;368(9):795-805.

63. Young D, Lamb SE, Shah S, MacKenzie I, Tunnicliffe W, Lall R, et al. Highfrequency oscillation for acute respiratory distress syndrome. N Engl J Med. 2013;368(9):806-13.

64. Guervilly C, Forel JM, Hraiech S, Demory D, Allardet-Servent J, Adda $M$, et al. Right ventricular function during high-frequency oscillatory ventilation in adults with acute respiratory distress syndrome. Crit Care Med. 2012;40(5):1539-45.

65. Gu XL, Wu GN, Yao YW, Shi DH, Song Y. Is high-frequency oscillatory ventilation more effective and safer than conventional protective ventilation in adult acute respiratory distress syndrome patients? A meta-analysis of randomized controlled trials. Crit Care. 2014;18(3):R111.

66. Meade MO, Young D, Hanna S, Zhou Q, Bachman TE, Bollen C, et al. Severity of hypoxemia and effect of high-frequency oscillatory ventilation in acute respiratory distress syndrome. Am J Respir Crit Care Med. 2017;196(6):727-33.

67. Sud S, Sud M, Friedrich JO, Meade MO, Ferguson ND, Wunsch H, et al. High frequency oscillation in patients with acute lung injury and acute respiratory distress syndrome (ARDS): systematic review and metaanalysis. BMJ. 2010;340:c2327. 
68. Sud S, Sud M, Friedrich JO, Wunsch H, Meade MO, Ferguson ND, et al. High-frequency ventilation versus conventional ventilation for treatment of acute lung injury and acute respiratory distress syndrome. Cochrane Database Syst Rev. 2013;(2):CD004085.

69. Klapsing P, Moerer O, Wende C, Herrmann P, Quintel M, Bleckmann A, et al. High-frequency oscillatory ventilation guided by transpulmonary pressure in acute respiratory syndrome: an experimental study in pigs. Crit Care. 2018;22(1):121.

70. Bendixen HH, Bullwinkel B, Hedley-Whyte J, Laver MB. Atelectasis and shunting during spontaneous ventilation in anesthetized patients. Anesthesiology. 1964;25:297-301.

71. Borges JB, Okamoto VN, Matos GF, Caramez MP, Arantes PR, Barros F, et al. Reversibility of lung collapse and hypoxemia in early acute respiratory distress syndrome. Am J Respir Crit Care Med. 2006;174(3):268-78.

72. Constantin JM, Godet T, Jabaudon M, Bazin JE, Futier E. Recruitment maneuvers in acute respiratory distress syndrome. Ann Transl Med. 2017:5(14):290.

73. Fan E, Wilcox ME, Brower RG, Stewart TE, Mehta S, Lapinsky SE, et al. Recruitment maneuvers for acute lung injury: a systematic review. Am J Respir Crit Care Med. 2008;178(11):1156-63.

74. Godet T, Constantin JM, Jaber S, Futier E. How to monitor a recruitment maneuver at the bedside. Curr Opin Crit Care. 2015;21(3):253-8.

75. Almarakbi WA, Fawzi HM, Alhashemi JA. Effects of four intraoperative ventilatory strategies on respiratory compliance and gas exchange during laparoscopic gastric banding in obese patients. Br J Anaesth. 2009;102(6):862-8.

76. Schreiter D, Reske A, Stichert B, Seiwerts M, Bohm SH, Kloeppel R, et al. Alveolar recruitment in combination with sufficient positive endexpiratory pressure increases oxygenation and lung aeration in patients with severe chest trauma. Crit Care Med. 2004;32(4):968-75.

77. Yang $\mathrm{GH}$, Wang $\mathrm{CY}$, Ning R. Effects of high positive end-expiratory pressure combined with recruitment maneuvers in patients with acute respiratory distress syndrome. Zhongguo Wei Zhong Bing Ji Jiu Yi Xue. 2011;23(1):28-31.

78. Hodgson CL, Tuxen DV, Davies AR, Bailey MJ, Higgins AM, Holland $\mathrm{AE}$, et al. A randomised controlled trial of an open lung strategy with staircase recruitment, titrated PEEP and targeted low airway pressures in patients with acute respiratory distress syndrome. Crit Care. 2011;15(3):R133.

79. Huh JW, Jung H, Choi HS, Hong SB, Lim CM, Koh Y. Efficacy of positive end-expiratory pressure titration after the alveolar recruitment manoeuvre in patients with acute respiratory distress syndrome. Crit Care. 2009;13(1):R22.

80. Jabaudon M, Godet T, Futier E, Bazin JE, Sapin V, Roszyk L, et al. Rationale, study design and analysis plan of the lung imaging morphology for ventilator settings in acute respiratory distress syndrome study (LIVE study): study protocol for a randomised controlled trial. Anaesth Crit Care Pain Med. 2017;36(5):301-6.

81. Kacmarek RM, Villar J, Sulemanji D, Montiel R, Ferrando C, Blanco J, et al. Open lung approach for the acute respiratory distress syndrome: a pilot, randomized controlled trial. Crit Care Med. 2016;44(1):32-42.

82. Xi XM, Jiang L, Zhu B, Group RM. Clinical efficacy and safety of recruitment maneuver in patients with acute respiratory distress syndrome using low tidal volume ventilation: a multicenter randomized controlled clinical trial. Chin Med J (Engl). 2010;123(21):3100-5.

83. Forel JM, Roch A, Marin V, Michelet P, Demory D, Blache JL, et al. Neuromuscular blocking agents decrease inflammatory response in patients presenting with acute respiratory distress syndrome. Crit Care Med. 2006;34(11):2749-57.

84. Gainnier M, Roch A, Forel JM, Thirion X, Arnal JM, Donati S, et al. Effect of neuromuscular blocking agents on gas exchange in patients presenting with acute respiratory distress syndrome. Crit Care Med. 2004;32(1):113-9.

85. Papazian L, Forel JM, Gacouin A, Penot-Ragon C, Perrin G, Loundou $A$, et al. Neuromuscular blockers in early acute respiratory distress syndrome. N Engl J Med. 2010;363(12):1107-16.

86. Huang DT, Angus DC, Moss M, Thompson BT, Ferguson ND, Ginde A, et al. Design and rationale of the reevaluation of systemic early neuromuscular blockade trial for acute respiratory distress syndrome. Ann Am Thorac Soc. 2017;14(1):124-33.
87. Alhazzani W, Alshahrani M, Jaeschke R, Forel JM, Papazian L, Sevransky $J$, et al. Neuromuscular blocking agents in acute respiratory distress syndrome: a systematic review and meta-analysis of randomized controlled trials. Crit Care. 2013;17(2):R43.

88. Guervilly C, Bisbal M, Forel JM, Mechati M, Lehingue S, Bourenne J, et al. Effects of neuromuscular blockers on transpulmonary pressures in moderate to severe acute respiratory distress syndrome. Intensive Care Med. 2017:43(3):408-18.

89. Moore L, Kramer CJ, Delcoix-Lopes S, Modrykamien AM. Comparison of cisatracurium versus atracurium in early ARDS. Respir Care. 2017;62(7):947-52.

90. Sottile PD, Kiser TH, Burnham EL, Ho PM, Allen RR, Vandivier RW, et al. An observational study of the efficacy of cisatracurium compared with vecuronium in patients with or at risk for acute respiratory distress syndrome. Am J Respir Crit Care Med. 2018;197(7):897-904.

91. Yoshida T, Torsani V, Gomes S, De Santis RR, Beraldo MA, Costa EL, et al. Spontaneous effort causes occult pendelluft during mechanical ventilation. Am J Respir Crit Care Med. 2013;188(12):1420-7.

92. Richard JC, Lyazidi A, Akoumianaki E, Mortaza S, Cordioli RL, Lefebvre JC, et al. Potentially harmful effects of inspiratory synchronization during pressure preset ventilation. Intensive Care Med. 2013;39(11):2003-10.

93. Brochard L, Slutsky A, Pesenti A. Mechanical ventilation to minimize progression of lung injury in acute respiratory failure. Am J Respir Crit Care Med. 2017;195(4):438-42.

94. Blanch L, Villagra A, Sales B, Montanya J, Lucangelo U, Lujan M, et al. Asynchronies during mechanical ventilation are associated with mortality. Intensive Care Med. 2015;41(4):633-41.

95. Thille AW, Rodriguez P, Cabello B, Lellouche F, Brochard L. Patient-ventilator asynchrony during assisted mechanical ventilation. Intensive Care Med. 2006;32(10):1515-22.

96. Putensen C, Zech S, Wrigge H, Zinserling J, Stuber F, Von Spiegel T, et al. Long-term effects of spontaneous breathing during ventilatory support in patients with acute lung injury. Am J Respir Crit Care Med. 2001;164(1):43-9.

97. Zhou Y, Jin X, LV Y, Wang P, Yang Y, Liang G, et al. Early application of airway pressure release ventilation may reduce the duration of mechanical ventilation in acute respiratory distress syndrome. Intensive Care Med. 2017:43(11):1648-59.

98. Rittayamai N, Beloncle F, Goligher EC, Chen L, Mancebo J, Richard JM, et al. Effect of inspiratory synchronization during pressure-controlled ventilation on lung distension and inspiratory effort. Ann Intensive Care. 2017;7(1):100.

99. Guerin C, Gaillard S, Lemasson S, Ayzac L, Girard R, Beuret P, et al. Effects of systematic prone positioning in hypoxemic acute respiratory failure: a randomized controlled trial. JAMA. 2004;292(19):2379-87.

100. Mancebo J, Fernandez R, Blanch L, Rialp G, Gordo F, Ferrer M, et al. A multicenter trial of prolonged prone ventilation in severe acute respiratory distress syndrome. Am J Respir Crit Care Med. 2006;173(11):1233-9.

101. Taccone P, Pesenti A, Latini R, Polli F, Vagginelli F, Mietto C, et al. Prone positioning in patients with moderate and severe acute respiratory distress syndrome: a randomized controlled trial. JAMA. 2009;302(18):1977-84.

102. Chan MC, Hsu JY, Liu HH, Lee YL, Pong SC, Chang LY, et al. Effects of prone position on inflammatory markers in patients with ARDS due to community-acquired pneumonia. J Formos Med Assoc. 2007;106(9):708-16

103. Fernandez R, Trenchs X, Klamburg J, Castedo J, Serrano JM, Besso $G$, et al. Prone positioning in acute respiratory distress syndrome: a multicenter randomized clinical trial. Intensive Care Med. 2008;34(8):1487-91.

104. Voggenreiter G, Aufmkolk M, Stiletto RJ, Baacke MG, Waydhas C, Ose C, et al. Prone positioning improves oxygenation in post-traumatic lung injury—a prospective randomized trial. J Trauma. 2005;59(2):333-41 (discussion 41-3).

105. Munshi L, Del Sorbo L, Adhikari NKJ, Hodgson CL, Wunsch H, Meade $\mathrm{MO}$, et al. Prone position for acute respiratory distress syndrome. A systematic review and meta-analysis. Ann Am Thorac Soc. 2017;14(Supplement_4):S280-8.

106. Gattinoni L, Carlesso E, Taccone P, Polli F, Guerin C, Mancebo J. Prone positioning improves survival in severe ARDS: a pathophysiologic 
review and individual patient meta-analysis. Minerva Anestesiol. 2010;76(6):448-54.

107. Peek GJ, Mugford M, Tiruvoipati R, Wilson A, Allen E, Thalanany MM, et al. Efficacy and economic assessment of conventional ventilatory support versus extracorporeal membrane oxygenation for severe adult respiratory failure (CESAR): a multicentre randomised controlled trial. Lancet. 2009;374(9698):1351-63.

108. Noah MA, Peek GJ, Finney SJ, Griffiths MJ, Harrison DA, Grieve R, et al. Referral to an extracorporeal membrane oxygenation center and mortality among patients with severe 2009 influenza A(H1N1). JAMA. 2011;306(15):1659-68.

109. Pham T, Combes A, Roze H, Chevret S, Mercat A, Roch A, et al. Extracorporeal membrane oxygenation for pandemic influenza A(H1N1)-induced acute respiratory distress syndrome: a cohort study and propensity-matched analysis. Am J Respir Crit Care Med. 2013;187(3):276-85

110. Combes A, Hajage D, Capellier G, Demoule A, Lavoue S, Guervilly C, et al. Extracorporeal membrane oxygenation for severe acute respiratory distress syndrome. N Engl J Med. 2018;378(21):1965-75.

111. Goligher EC, Tomlinson G, Hajage D, Wijeysundera DN, Fan E, Juni P, et al. Extracorporeal membrane oxygenation for severe acute respiratory distress syndrome and posterior probability of mortality benefit in a post hoc Bayesian analysis of a randomized clinical trial. JAMA. 2018;320(21):2251-9.

112. Allardet-Servent J, Castanier M, Signouret T, Soundaravelou R, Lepidi A, Seghboyan JM. Safety and efficacy of combined extracorporeal $\mathrm{CO}_{2}$ removal and renal replacement therapy in patients with acute respiratory distress syndrome and acute kidney injury: the pulmonary and renal support in acute respiratory distress syndrome study. Crit Care Med. 2015;43(12):2570-81.

113. Bein T, Weber-Carstens S, Goldmann A, Muller T, Staudinger T, Brederlau $\mathrm{J}$, et al. Lower tidal volume strategy (approximately $3 \mathrm{ml} / \mathrm{kg}$ ) combined with extracorporeal $\mathrm{CO}_{2}$ removal versus 'conventional' protective ventilation $(6 \mathrm{ml} / \mathrm{kg}$ ) in severe ARDS: the prospective randomized Xtraventstudy. Intensive Care Med. 2013;39(5):847-56.

114. Fanelli V, Ranieri MV, Mancebo J, Moerer O, Quintel M, Morley S, et al. Feasibility and safety of low-flow extracorporeal carbon dioxide removal to facilitate ultra-protective ventilation in patients with moderate acute respiratory distress sindrome. Crit Care. 2016;20:36.

115. Forster C, Schriewer J, John S, Eckardt KU, Willam C. Low-flow CO(2) removal integrated into a renal-replacement circuit can reduce acidosis and decrease vasopressor requirements. Crit Care. 2013;17(4):R154.

116. Hermann A, Riss K, Schellongowski P, Bojic A, Wohlfarth P, Robak O, et al. A novel pump-driven veno-venous gas exchange system during extracorporeal $\mathrm{CO}_{2}$-removal. Intensive Care Med. 2015;41(10):1773-80

117. Nierhaus A, Frings DP, Braune S, Baumann HJ, Schneider C, Wittenburg $B$, et al. Interventional lung assist enables lung protective mechanical ventilation in acute respiratory distress syndrome. Minerva Anestesiol. 2011;77(8):797-801.

118. Schmidt M, Jaber S, Zogheib E, Godet T, Capellier G, Combes A. Feasibility and safety of low-flow extracorporeal $\mathrm{CO}_{2}$ removal managed with a renal replacement platform to enhance lung-protective ventilation of patients with mild-to-moderate ARDS. Crit Care. 2018;22(1):122

119. Winiszewski H, Aptel F, Belon F, Belin N, Chaignat C, Patry C, et al. Daily use of extracorporeal $\mathrm{CO}_{2}$ removal in a critical care unit: indications and results. J Intensive Care. 2018;6:36.

120. Zimmermann M, Bein T, Arlt M, Philipp A, Rupprecht L, Mueller T, et al. Pumpless extracorporeal interventional lung assist in patients with acute respiratory distress syndrome: a prospective pilot study. Crit Care. 2009;13(1):R10.

121. Terragni PP, Del Sorbo L, Mascia L, Urbino R, Martin EL, Birocco A, et al. Tidal volume lower than $6 \mathrm{ml} / \mathrm{kg}$ enhances lung protection: role of extracorporeal carbon dioxide removal. Anesthesiology. 2009;111(4):826-35.

122. Bein T, Weber F, Philipp A, Prasser C, Pfeifer M, Schmid FX, et al. A new pumpless extracorporeal interventional lung assist in critical hypoxemia/hypercapnia. Crit Care Med. 2006;34(5):1372-7.

123. Liebold A, Philipp A, Kaiser M, Merk J, Schmid FX, Birnbaum DE. Pumpless extracorporeal lung assist using an arterio-venous shunt. Applications and limitations. Minerva Anestesiol. 2002;68(5):387-91.
124. Munoz-Bendix C, Beseoglu K, Kram R. Extracorporeal decarboxylation in patients with severe traumatic brain injury and ARDS enables effective control of intracranial pressure. Crit Care. 2015;19:381.

125. Weber-Carstens S, Bercker S, Hommel M, Deja M, MacGuill M, Dreykluft $C$, et al. Hypercapnia in late-phase ALI/ARDS: providing spontaneous breathing using pumpless extracorporeal lung assist. Intensive Care Med. 2009;35(6):1100-5.

126. Taccone FS, Malfertheiner MV, Ferrari F, Di Nardo M, Swol J, Broman LM, et al. Extracorporeal $\mathrm{CO}_{2}$ removal in critically ill patients: a systematic review. Minerva Anestesiol. 2017;83(7):762-72.

127. Howlett R. Nobel award stirs up debate on nitric oxide breakthrough. Nature. 1998;395(6703):625-6.

128. Griffiths MJ, Evans TW. Inhaled nitric oxide therapy in adults. N Engl J Med. 2005;353(25):2683-95.

129. Wang X, Tanus-Santos JE, Reiter CD, Dejam A, Shiva S, Smith RD, et al. Biological activity of nitric oxide in the plasmatic compartment. Proc Natl Acad Sci U S A. 2004;101(31):11477-82.

130. Frostell C, Fratacci MD, Wain JC, Jones R, Zapol WM. Inhaled nitric oxide. A selective pulmonary vasodilator reversing hypoxic pulmonary vasoconstriction. Circulation. 1991;83(6):2038-47.

131. Rossaint R, Falke KJ, Lopez F, Slama K, Pison U, Zapol WM. Inhaled nitric oxide for the adult respiratory distress syndrome. N Engl I Med. 1993;328(6):399-405.

132. Gebistorf F, Karam O, Wetterslev J, Afshari A. Inhaled nitric oxide for acute respiratory distress syndrome (ARDS) in children and adults. Cochrane Database Syst Rev. 2016;(6):CD002787.

133. Gerlach H, Keh D, Semmerow A, Busch T, Lewandowski K, Pappert DM, et al. Dose-response characteristics during long-term inhalation of nitric oxide in patients with severe acute respiratory distress syndrome: a prospective, randomized, controlled study. Am J Respir Crit Care Med. 2003;167(7):1008-15

134. Gerlach H, Pappert D, Lewandowski K, Rossaint R, Falke KJ. Longterm inhalation with evaluated low doses of nitric oxide for selective improvement of oxygenation in patients with adult respiratory distress syndrome. Intensive Care Med. 1993;19(8):443-9.

135. Dellinger RP, Zimmerman JL, Taylor RW, Straube RC, Hauser DL, Criner $\mathrm{GJ}$, et al. Effects of inhaled nitric oxide in patients with acute respiratory distress syndrome: results of a randomized phase II trial. Inhaled Nitric Oxide in ARDS Study Group. Crit Care Med. 1998;26(1):15-23.

136. Lundin S, Mang H, Smithies M, Stenqvist O, Frostell C. Inhalation of nitric oxide in acute lung injury: results of a European multicentre study. The European Study Group of Inhaled Nitric Oxide. Intensive Care Med. 1999;25(9):911-9.

137. Michael JR, Barton RG, Saffle JR, Mone M, Markewitz BA, Hillier K, et al. Inhaled nitric oxide versus conventional therapy: effect on oxygenation in ARDS. Am J Respir Crit Care Med. 1998;157(5 Pt 1):1372-80.

138. Park KJ, Lee YJ, Oh YJ, Lee KS, Sheen SS, Hwang SC. Combined effects of inhaled nitric oxide and a recruitment maneuver in patients with acute respiratory distress syndrome. Yonsei Med J. 2003:44(2):219-26.

139. Taylor RW, Zimmerman JL, Dellinger RP, Straube RC, Criner GJ, Davis K Jr, et al. Low-dose inhaled nitric oxide in patients with acute lung injury: a randomized controlled trial. JAMA. 2004;291(13):1603-9.

140. Troncy E, Collet JP, Shapiro S, Guimond JG, Blair L, Ducruet T, et al. Inhaled nitric oxide in acute respiratory distress syndrome: a pilot randomized controlled study. Am J Respir Crit Care Med. 1998;157(5 Pt 1):1483-8.

141. McMahon TJ, Moon RE, Luschinger BP, Carraway MS, Stone AE, Stolp BW, et al. Nitric oxide in the human respiratory cycle. Nat Med. 2002;8(7):711-7.

142. Troncy E, Francoeur M, Salazkin I, Yang F, Charbonneau M, Leclerc G, et al. Extra-pulmonary effects of inhaled nitric oxide in swine with and without phenylephrine. Br J Anaesth. 1997;79(5):631-40.

143. Weinberger B, Laskin DL, Heck DE, Laskin JD. The toxicology of inhaled nitric oxide. Toxicol Sci. 2001;59(1):5-16.

144. Ruan SY, Huang TM, Wu HY, Wu HD, Yu CJ, Lai MS. Inhaled nitric oxide therapy and risk of renal dysfunction: a systematic review and metaanalysis of randomized trials. Crit Care. 2015;19:137.

\section{Publisher's Note}

Springer Nature remains neutral with regard to jurisdictional claims in published maps and institutional affiliations. 